\title{
EXPLORING THE PROTECTIVE ROLE OF SIBLINGS IN SHY CHILDREN'S SOCIO-EMOTIONAL ADJUSTMENT
}

\begin{abstract}
Allison A. Graham
A thesis presented to Carleton University in partial fulfillment of the thesis requirements for the degree of Master of Arts in Psychology

Department of Psychology

Carleton University

September, 2009

(C) 2009 Allison A. Graham
\end{abstract}




$\begin{array}{ll}\begin{array}{l}\text { Library and Archives } \\ \text { Canada }\end{array} & \begin{array}{l}\text { Bibliothèque et } \\ \text { Archives Canada }\end{array} \\ \begin{array}{l}\text { Published Heritage } \\ \text { Branch }\end{array} & \begin{array}{l}\text { Direction du } \\ \text { Patrimoine de l'édition }\end{array} \\ \begin{array}{l}\text { 395 Wellington Street } \\ \text { Ottawa ON K1A ON4 } \\ \text { Canada }\end{array} & \begin{array}{l}\text { 395, rue Wellington } \\ \text { Ottawa ON K1A ON4 } \\ \text { Canada }\end{array}\end{array}$

Your file Votre référence

ISBN: 978-0-494-60307-9

Ourfile Notre référence

ISBN: 978-0-494-60307-9

\section{NOTICE:}

The author has granted a nonexclusive license allowing Library and Archives Canada to reproduce, publish, archive, preserve, conserve, communicate to the public by telecommunication or on the Internet, loan, distribute and sell theses worldwide, for commercial or noncommercial purposes, in microform, paper, electronic and/or any other formats.

The author retains copyright ownership and moral rights in this thesis. Neither the thesis nor substantial extracts from it may be printed or otherwise reproduced without the author's permission.
AVIS:

L'auteur a accordé une licence non exclusive permettant à la Bibliothèque et Archives Canada de reproduire, publier, archiver, sauvegarder, conserver, transmettre au public par télécommunication ou par l'internet, prêter, distribuer et vendre des thèses partout dans le monde, à des fins commerciales ou autres, sur support microforme, papier, électronique et/ou autres formats.

L'auteur conserve la propriété du droit d'auteur et des droits moraux qui protège cette thèse. Ni la thèse ni des extraits substantiels de celle-ci ne doivent être imprimés ou autrement reproduits sans son autorisation.
In compliance with the Canadian Privacy Act some supporting forms may have been removed from this thesis.

While these forms may be included in the document page count, their removal does not represent any loss of content from the thesis.
Conformément à la loi canadienne sur la protection de la vie privée, quelques formulaires secondaires ont été enlevés de cette thèse.

Bien que ces formulaires aient inclus dans la pagination, il n'y aura aucun contenu manquant.

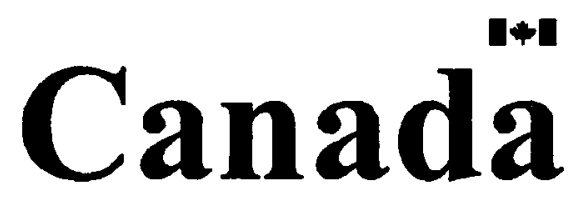




\begin{abstract}
The purpose of this thesis research was to examine the moderating role of sibling relationship quality (SRQ) in the associations between shyness and negative socioemotional adjustment. Participants were $n=79$ preschool and daycare children (aged 4 6 yrs, $M=4.74$ yrs) who had at least one sibling. The sibling closest in age was chosen for SRQ ratings ( 7 months $-17 \mathrm{yrs}, M=5.15 \mathrm{yrs}$ ). Parents completed ratings of child shyness and SRQ. Teachers completed ratings of child social adjustment at preschool. Children rated their loneliness, perceived cognitive competence and peer acceptance, and SRQ. Results indicated that shyness was positively associated with withdrawn behaviour and negatively associated with perceived cognitive competence and prosocial behaviour. Positive sibling relationships were associated with less loneliness for all children. In addition, a closer and warmer sibling relationship appeared to protect shy children from loneliness and anxious-fearful behaviour at preschool. The results are discussed in terms of the protective role siblings may play in shy children's socio-emotional development.
\end{abstract}




\section{Acknowledgements}

I would like to thank the many people who helped support and encourage me in this academic endeavour. First, I would like to thank my advisor, Dr. Robert Coplan, who encouraged me to complete my M.A. degree and who supported and guided me throughout this project. I would also like to thank the members of my committee for donating their time and wisdom to this research. To all the parents and children who consented to participation, for without them this research would not have been possible. In addition, I would like to thank my parents, and recently extended family, for all their support and understanding through this journey. Thank you to my lab-mates who offered their wisdom and experience in order to better this research. Finally I would like to thank my fiancé for all his love and support, for always having faith in my abilities, and for helping me to believe in myself. 
Table of Contents

Abstract

List of Tables and Figures $\quad$ vi

List of Appendices $\quad$ vii

Introduction $\quad 1$

Conceptual Mechanisms of Influence 3

$\begin{array}{ll}\text { Importance of Sibling Relationships } & 7\end{array}$

$\begin{array}{ll}\text { Socio-cognitive skills } & 7\end{array}$

$\begin{array}{lr}\text { Conflict and conflict resolution } & 10\end{array}$

$\begin{array}{lr}\text { Prosocial behaviour } & 12\end{array}$

Parent-Child, Sibling and Peer Relationships $\quad 14$

$\begin{array}{lr}\text { Family Structure Variables } & 16\end{array}$

$\begin{array}{lr}\text { Ordinal positioning/birth order } & 16\end{array}$

$\begin{array}{lr}\text { Sex composition } & 18\end{array}$

$\begin{array}{ll}\text { Age Spacing } & 19\end{array}$

Siblings and Socio-Emotional Outcomes $\quad 19$

Sibling and Peer Relationships: Models of Risk and Protection 21

$\begin{array}{ll}\text { Support for the carryover model } & 23\end{array}$

$\begin{array}{lr}\text { Support for the compensation model } & 25\end{array}$

$\begin{array}{ll}\text { Shyness in Early Childhood } & 27\end{array}$

$\begin{array}{ll}\text { Biological Expression } & 30\end{array}$

Environmental Influences $\quad 32$

Shyness and Socio-Emotional Adjustment 36 
Method

Participants

Procedure

Measures

Results

Outliers and Statistical Assumptions

Descriptive and Correlational Analyses

Hierarchical Regression Analyses

Discussion

Shyness and Adjustment

Siblings Relationships and Adjustment

Family Structure Variables

Shyness, Sibling Relationships, and Outcomes

Limitations and Future Directions

Conclusions

References 


\section{List of Tables and Figures}

Table 1: Correlations between Independent Variables and SocioEmotional Outcome Variables

Table 2: Correlations between Socio-Emotional Outcome Variables

Table 3: Results of Hierarchical Regression Analyses Predicting Indices of Adjustment from Interactions between Shyness, Self and ParentRated SRQ and Birth Order

Figure 1: Interactions between Shyness and Parent-Rated SRQ in the Prediction of Teacher-Rated Anxious-Fearful Behaviour

Figure 2: Interactions between Shyness and Self-Rated SRQ in the Prediction of Self-Rated Loneliness 


\section{List of Appendices}

$\begin{array}{ll}\text { Appendix A: Information and Consent Form } & 109\end{array}$

Appendix B: Scripts for Recruitment and Child Individual Interviews 112

Appendix C: Demographic Information 114

Appendix D: Parent Rated Child Shyness Questionnaire 115

Appendix E: Teacher Rated Socio-Emotional Functioning 116

Appendix F: Self-Perceptions of Social and Cognitive Competence 117

Appendix G: Child Loneliness Questionnaire 118

Appendix H: Child and Parent Sibling Appraisal Questionnaires 119 


\section{Exploring the Protective Role of Siblings in \\ Shy Children's Socio-Emotional Adjustment}

In last two decades the sibling relationship has emerged as an important supportive and learning environment for children to develop and practice their social and cognitive skills, such as cooperation (Dunn \& Dale, 1984; Dunn \& Munn, 1986), affective perspective taking, emotional understanding (Brody, 1998; Howe, 1991; Howe \& Ross, 1990; Stewart \& Marvin, 1984; Youngblade \& Dunn, 1995) and conflict resolution (Brown \& Dunn, 1992; Ross, Ross, Stein \& Trabasso, 2006). The quality of sibling relationships may be particularly relevant to children's adjustment because of children's familiarity with one another, as well as the emotionally powerful nature of these relationships which are often characterized by intense positive and negative affect (e.g., Kramer, 2008). Social interactions between siblings are also frequent and uninhibited throughout early and middle childhood (Boer \& Dunn, 1992). In fact children have been shown to spend more time with siblings than with parents during early to middle childhood (McHale \& Crouter, 1996). It is also in their interactions with siblings that children in early childhood have their most intensive social experiences (Dunn, 1984; Dunn \& Dale, 1984).

The literature suggests that sibling relationships that are either high in warmth (i.e., affection and intimacy) or displaying a balance of warmth and conflict predict the best socio-emotional adjustment outcomes (Hetherington, 1988; McGuire, McHale \& Updegraff, 1996; Stormshak, Bellanti \& Bierman, 1996). However, to date, researchers have not explored the role of siblings in the socio-emotional adjustment of shy children. Many researchers have suggested that shy children are at risk for internalizing problems 
such as loneliness, depression (Burgess, Rubin, Cheah \& Nelson, 2001; Rubin \& Mills, 1988), and negative self-perceptions (Fordham \& Stevenson-Hinde, 1999; Hymel, Bowker, \& Woody, 1993), as well peer rejection and withdrawal (Cassidy \& Asher, 1992). Thus, identifying protective factors that prevent shy children from suffering longterm socio-emotional difficulties is essential.

Only one study to date has specifically looked at the protective role of siblings for isolated children, who, like shy children, also experience peer problems (East \& Rook, 1992). Although the outcomes may not be the same for shy children, conceptually the social and cognitive skills shy children learn through sibling interaction may transfer to their peer relationships. The support they receive from their involvement in good quality sibling relationships may also help to lower their internalizing problems.

Another avenue of thought suggests that children may compensate for poor peer relations at school through a close and supportive relationship at home or vice versa (East \& Rook, 1992; Mendelson, Aboud, \& Lanthier, 1994; Stocker \& Dunn, 1990; Volling, Youngblade \& Belsky, 1997). From this perspective, shy children, who have been found to be at risk for peer rejection as early as 4 years of age (Coplan, Prakash, O'Neil, \& Armer, 2004), may compensate for poor relationships at school through a supportive and nurturing sibling relationship.

The main goal of this thesis research was to explore the role of siblings in the socio-emotional functioning of shy children. In particular, the protective role of sibling relationship quality in the association between shyness and negative adjustment outcomes (i.e., loneliness, negative self-perceptions, and poor peer relations) was explored. This study examined the preschool age since this may be a relevant time period in children's 
development as they transition from interactions primarily within the family to more frequent interactions with peers at school.

A discussion of the literature concerning the relevant theories illustrating the mechanisms of influences between parent, sibling and peer relations is followed by a discussion of the importance of sibling relationships, family processes in relation to sibling relationships, family structure variables, siblings and socio-emotional outcomes, and siblings and peer relationships. Finally, the literature concerning shyness in early childhood is discussed, followed by a discussion of the role of sibling relationships for shy children.

Conceptual Mechanisms of Influence between Sibling Relationships and Peer Relations

Attachment theory proposes that children develop internal working models of relationships through their primary caregiver, which are then carried forward to other relationships, including relationships with siblings and peers, and later intimate relations (Bowlby, 1973; Bretherton, 1988). Attachment with a primary caregiver involves the development of a sense of basic confidence or trust, which permits the child to interact with the environment in appropriate and adaptive ways (Ainsworth, 1972; Anisworth, Blehar, Waters, \& Wall, 1978; Bowlby, 1969; Sroufe \& Fleeson, 1986). Early attachment is viewed as important for later social competence and for the ability to form close relationships during childhood, adolescence and adulthood (Sroufe \& Fleeson, 1986).

This theory suggests that siblings who have an insecure attachment will re-enact aspects of the non-nurturant caregiver, and children who have a secure attachment will re-enact aspects of the nurturant caregiver in their interactions with each other and their peers (Dunn \& McGuire, 1992). Researchers have shown that secure attachment predicts 
social competence whereas an insecure attachment predicts both externalizing and internalizing problems from early childhood to adolescence (Calkins \& Fox, 1992; Booth, Rose-Krasnor, McKinnon, \& Rubin, 1994; Rose-Krasnor, Rubin, Booth, \& Coplan, 1996; Shamir-Essakow, Ungerer, \& Rapee, 2005; van Brakel, Muris, Bogels, \& Thomassen, 2006). Alternatively, sibling relationships may involve their own internal models, whereby younger children develop confidence and trust as well as social skills from their older siblings, which then influence their relationships with other children (Mendelson et al., 1994).

Family Systems Theory (Minuchin, 1988) provides a framework to understanding how relationships within the family affect one another. This perspective does not assume the family is a homogeneous group, but assumes all relationships in the family are interactional and reciprocal, in which the behaviour of one individual affects the behaviour of others in the family as well as the family as a whole, which in turn will affect relationships outside the family.

For example, parental differential treatment has effects not only for the sibling who is favoured, but also on the adjustment (internalizing and externalizing) of both children. The children's adjustment problems may then have an effect on the parental hostility shown towards them (Richmond \& Stocker, 2008). Research also suggests links between parent-child relationships and relationships with siblings and peers (e.g., Dunn \& McGuire, 1992; Stocker, 1994)

Sibling influences can also be considered using Vygotsky's (1962) Scaffolding Theory. Using this theory, social agents such as parents, siblings or peers, with more highly developed cognitive skills help guide children's learning by providing them with a 
framework and a context to practice more sophisticated socio-cognitive skills (Brody, 1998). In other words, intellectual growth is viewed as a process of internalizing the knowledge already incorporated in the social interaction.

Mothers scaffolding during games and interactions are thought to be important for children's subsequent development (Vandell \& Wilson, 1987). During scaffolding the amount of support mothers provide changes with the child's interaction skills. As children become more skilled they are able to participate more in games and interactions, and maternal support decreases. There is less research concerning the extent to which siblings may scaffold turn-taking exchanges, however, there is some research suggesting that scaffolding by both mothers and siblings has effects on subsequent peer relationships (Vandell \& Wilson, 1987).

Some Theory of Mind theorists view conceptual and intellectual development as a process of theory acquisition whereby children acquire a coherent body of knowledge and new ways of thinking that goes beyond the immediately perceptible and which provides predictive power (e.g., Carey, 1985; Gopnick, 1988; Perner, 1991; Perner, Ruffman, \& Leekam, 1994). For example, theory of mind is often tested using a "false belief question" which requires not only understanding of the conditions under which a belief is formed but also to be able to represent the world as it is not (misrepresentation of the world).

It is speculated that children who live in a world rich in incentive and opportunity to benefit from advanced theory of mind will develop of theory of mind more quickly than those in environments less rich with opportunity (Perner et al., 1994). Perner and colleagues (1994) advocated that family size may play an important role in theory 
acquisition by suggesting that children who have siblings to work and play with should have an advantage over children who only socialize with their parents. Perner and colleagues (1994) tested this theory in a study of 3-and 4-year-olds and found that the number of siblings in a family was positively related to young children's reasoning in theory of mind tasks. In a follow up study, Jenkins and Astington (1996) found that this association remained even after the effects of age and a general measure of language competence was partialed out.

Bandura's $(1977,1986)$ Social Cognitive/Learning Theory suggests that exposure to friends, family and role models shape children's beliefs and attitudes. Behaviour is not thought to originate in the child's own cognitions, but rather in the attitudes and behaviours of the individuals who serve as the child's role models (i.e., parents, siblings and peers). Learned behaviours are more likely to occur when interactions between the child and these individuals are frequent and intense or if the individual is someone the adolescent admires or looks up to (Bahr, Hoffmann, \& Yang, 2005). These learned behaviours are then thought to generalize to their interactions with peers and friends. Since sibling interactions in early childhood are frequent and intense it is a particularly salient context for social learning to take place, especially for the younger sibling who may be more influenced by the older more dominant sibling.

For example, children in conflictual sibling relationships may imitate the aggressive and hostile behaviour they experience with their siblings in other contexts (Brody, Stoneman \& Burke, 1987; i.e., school, peer activities), leading to externalizing as well as internalizing problems (Stocker, Burwell \& Briggs, 2002). In contrast, if children experience warm and nurturing sibling relationships, these children may develop 
prosocial behaviours and positive relationships with their peers and this may be especially true for younger siblings (Dunn \& Munn, 1986).

\section{Importance of Sibling Relationships}

There has been much research on the developmental importance of parent-child relationships (e.g. Ainsworth et al., 1978; Bowlby, 1973). However, in contemporary psychology, there has been an increased interest in the study of siblings as important agents of social and cognitive development. Theorists, such as Piaget (1965) and Sullivan (1953), clinicians, such as Adler (1958) and Winnicott (1975) and more recently, family systems theorists (e.g., Minuchin, 1988) have all stressed the significance of peer interaction in children's social development. Thus, it makes theoretical sense that interactions between siblings should also be of importance, particularly given the intimacy and intensity of these relationships. The first studies on siblings were conducted over 100 years ago by Sir Francis Galton (in Brody, 1998). However, researchers have only just begun to study the dynamic processes of sibling relationships and its relations to family and peer processes. For example, children's relationships with siblings have been studied as a context of intellectual advancement, where children learn perspective taking skills, cooperation, conflict resolution, and prosocial behaviour (Azmitia \& Hesser, 1993; Brody, 1998; Dunn \& Munn, 1986; Howe \& Ross, 1990; Perner et al., 1994; Stewart \& Marvin, 1984).

Socio-cognitive skills. In accordance with Vygotsky's (1962) scaffolding theory, the literature suggests that older siblings in middle childhood can effectively teach their younger siblings conceptual knowledge (Brody, 1998; Cicirelli, 1972). Although their approach to teaching differs from that used by adults, siblings have been found to be 
more effective teachers than peers (Azmitia \& Hesser; Perez-Granados \& Callanan, 1997). For example, Azmitia and Hesser (1993) found that young children (aged 5-6 years) were more likely to observe, imitate, and consult their older siblings (aged 7-9 years) than their older peers on a model construction task. In a teaching task, older siblings provided more explanations, positive feedback and gave learners more control of the task than older peers. Younger siblings also prompted the siblings' explanations and pressured them into giving them more control of the task, more so than with their older peers. Moreover, children taught by siblings obtained higher post-test scores than children taught by peers. These findings highlight the uniqueness of the sibling relationship in providing guidance and teaching as well as familiar, safe environment for reciprocal interaction.

Research also suggests that children's interactions with their siblings are linked to the understanding of "other minds", such as affective perspective taking skills; the ability to put themselves in another's' shoes and understand their feelings and beliefs (Howe, 1991; Howe \& Ross, 1990; Perner et al., 1994; Stewart \& Marvin, 1984). Several studies have proposed that children come to understand other people's minds and their own past mental states, feelings and beliefs through role taking and pretend play with their siblings (e.g., Cutting \& Dunn, 2006; Dunn \& Dale, 1984; Youngblade \& Dunn, 1995). It has been noted that young children engage more frequently in creative role taking with siblings more than anyone else (Dunn \& Dale, 1984).

For example, in a longitudinal study, Youngblade and Dunn (1995) found that the pretend play of 3-year-old children and their older siblings was more strongly related to children's performance on an affective understanding task than mother-infant interaction. 
Early social pretend play was also significantly related to the child's developing understanding of other people's feelings and beliefs as well as their mastery of the relation between mental life and real life.

In an examination of the pretend play of 2-year-old children with their mothers and siblings, Dunn and Dale (1984) also found that siblings play an important role. As opposed to mothers, who were more likely to adopt the "interested spectator" role, older siblings would enter into the joint game as a full participant by performing pretend actions and adopting pretend identities complementary to the child's pretend performance. Furthermore, sibling interactions provided the context for the transformation of role identity, location and psychological state when the younger siblings were as young as 18 months old, and this type of play did not occur in interactions between mother and child. In addition, Cutting and Dunn (2006) found links between the successful conversational interactions of 4-year-old children with their siblings and their social cognitive development including their emotional understanding. In addition, research suggests an association between preschooler's perspective taking skills and friendly sibling relations (e.g., Stewart \& Marvin, 1984; Youngblade \& Dunn, 1995). For example, Stewart and Marvin (1984) reported that preschooler's perspective-taking ability was positively associated with and their ability to provide caretaking for their infant siblings in the mother's absence during a modified strange situation. More recent researchers have also reported similar results (Howe, 1991; Howe \& Ross, 1990).

Furthermore, several studies suggest that children's experiences and interactions with their parents and siblings can affect their interactions with their peers (e.g., Vandell 
\& Wilson, 1987; Youngblade \& Dunn, 1995). For instance, in support of Vygotsky's scaffolding theory, Vandell and Wilson (1987) found that infants' turn-taking experiences with their mothers were related to infants' subsequent turn-taking exchanges with their peers. Although infants' exchanges with older siblings were briefer and older siblings did not respond contingently to the infants' interests and actions, the infants' interaction experiences with their older siblings were still positively related to their subsequent peer interaction.

In light of this research, older siblings can be effective teachers to their younger siblings and can provide play opportunities, particularly pretend play, for their younger siblings to practice their social-cognitive skills and this practice may transfer to their interactions with their peers (Vandell \& Wilson, 1987; Youngblade \& Dunn, 1995).

Conflict and conflict resolution. Because of the intimacy and familiarity of sibling relationships, combined with their sometimes incompatible goals, sibling conflict is inevitable and to a certain degree is normative (Ross et al., 2006; Stocker et al., 2002). Although the presence of friendly sibling relations provides opportunities for older siblings to teach younger siblings cognitive and social skills (Howe \& Ross, 1990; Vandell \& Wilson, 1987), conflict in sibling relationships may have both negative and positive influences on adjustment.

Conflict in sibling relationships has been linked to externalizing as well as internalizing problems (Dunn, Slomkowski, Beardsall \& Rende, 1994; Stocker et al., 2002). Research suggests that the aggressive and hostile behaviour of one sibling can influence the behaviour and adjustment of the other sibling (Beardsall \& Dunn, 1992; Brody et al., 1987). Patterson and colleagues (Patterson, 1986; Patterson, Dishion \& 
Bank, 1984) also suggest that siblings play a shaping role in the development of aggressive behaviour toward peers in both clinical and normal populations. It was found that the coercive behaviour of a child toward their sibling was linked to the sibling's problems with peers outside the family. In addition, Marks, Ensor and Hughes (2009) report that children 3 to 6 years of age who show sustained, frequent antisocial behaviour toward their siblings were more likely to refuse to share with and bully unfamiliar peers. Furthermore, epidemiological studies report poor relations with siblings to be more common in children with other behaviour problems (Patterson, 1986; Richman, Stevenson \& Graham, 1982).

Although conflict in sibling relationships can be negative, some theorists also suggest that conflict is not always detrimental. For example, it has been argued that conflict can provide siblings with the opportunity to express their feelings and practice their communication and cooperation skills (Piaget, 1932). Sibling conflict has also been found to elicit the most maternal talk about feeling states and moral issues which elicits reflection on motives, intentions, and knowledge (Dunn, Bretherton, \& Munn, 1987). In addition, sibling conflicts also offer the opportunity for persuasive negotiation in which individuals clarify their differing perspectives and seek collaborative resolutions (Herrera \& Dunn, 1997; Ross et al., 2006). For example, Ross and colleagues (2006) found that older sibling's appraisals of their younger sibling were associated with the outcomes of negotiations and with the strategies older siblings adopted during these negotiations. When older siblings rated their younger counterparts more favourably, they were less likely to accuse and dismiss and more likely to engage in counterarguments, resulting in 
an outcome of compromise. Thus, the quality of the sibling relationship may be related to the acquisition of better conflict resolution skills.

Both conflict and warmth have been linked to children's development of social competence, positive peer relationships and school adjustment (Brown \& Dunn, 1992; Hetherington, 1988; Howe \& Ross, 1990; Stormshak et al., 1996). Several studies suggest that a balance between support and conflict have positive effects on psychosocial competence by providing behavioural competencies that are linked to managing conflict as well as providing support and nurturance. For instance, Howe and Ross (1990) found that sibling interactions that included both negative conflictual exchanges and positive discussion of feelings were positively linked to care giving during early childhood. Stormshak and colleagues (1996) also found that children in involved sibling relationships (moderate conflict, moderate warmth) were rated by teachers as having more emotional control and social competence than children in conflictual relationships (high conflict, low warmth) in a sample of children with behaviour problems.

Prosocial behaviour. Not only do siblings have the ability to teach younger siblings cognitive (Howe \& Ross, 1990) as well as social skills (Vandell \& Wilson, 1987), but siblings can also help each other develop prosocial skills (Dunn, 2001; Dunn \& Dale, 1984; Dunn \& Munn, 1986; Tucker, Updegraff, McHale, \& Crouter, 1999). To behave in a prosocial manner depends not only on the capability of recognizing the needs and feelings of another person, but the motivation to act in a positive manner to that recognition (Dunn \& Munn, 1986). Research suggests that children's attention to the needs of others emerges in infancy, and their ability to direct their social behaviour toward meeting those needs increases rapidly through the toddler and preschooler periods 
(Hastings, Zahn-Waxler, \& McShane, 2006). Mothers report that during their second year, children at home show increasing sensitivity to the distress of others (Cummings, Zahn-Waxler \& Radke-Yarrow, 1981). Although, Zahn-Waxler, Radke-Yarrow and Brady-Smith (1977) suggest that as children become more empathetic with age, they also become more competitive and protective of privacy.

In line with this theory, Buhrmester and Furman (1992) found that the sibling relationship becomes significantly less intense with age, in a variety of ways, including the level of warmth and support directed toward their sibling. Sibling support reported by both siblings was significantly higher in $4^{\text {th }}$ grade than in $7^{\text {th }}$ grade, although these levels increased in middle to late adolescence. Cole and Kerns (2001) also found a U-shaped pattern with respect to prosocial behaviour.

In a study of the development of prosocial behaviour, Dunn and Munn (1986) reported that by 18 months, children were capable of sharing, helping and comforting, however cooperative behaviour was more frequently shown. Conciliation and cooperative behaviour was more frequently shown by 2 -year olds whose sibling had previously been cooperative. These results suggest that children who grow up with a sibling, who interacts with them in a cooperative way most of the time, will themselves develop more cooperative behaviours. Moreover, it is possible that siblings influence some aspects of prosocial behaviour independently of the influence of their parents. Dunn \& Dale (1984) have also shown that cooperative play, especially social fantasy play, is more commonly shown by children whose older siblings have been especially friendly towards them and mothers were also shown to rarely take part in such social pretend play. In more recent research, Tucker and colleagues (1999) found that younger siblings' empathy was 
associated with their older sibling's empathic behaviour in late childhood, however, this effect was more pronounced with older brothers than sisters.

These studies suggest that the development of prosocial behaviour tends to develop during friendly sibling relations or with a sibling who has previously been cooperative or empathic (Dunn \& Dale, 1984; Dunn \& Munn, 1986; Tucker et al., 1999). However, the mechanisms as to how these friendly sibling relations develop are still unclear. These possible mechanisms may involve attachment and parent-child relations, which will be discussed in the next section.

Parent-Child, Sibling and Peer Relationships

As we have seen in the previous section, the sibling relationship is important for children's social development, however family systems theory (Minuchin, 1988) suggests that this relationship is also affected by other relationships in the family, such as the parent-child relationship, as well as peer relationships outside the family. Contemporary research has reported links between parent-child relationships and children's relationships with siblings and peers (e.g., Dunn \& McGuire, 1992; Stocker, 1994).

For instance, in a study of 85 second-graders, Stocker (1994) found that children who perceived low levels of warmth in their relationships with both mothers and friends had significantly worse socio-emotional outcomes (i.e., loneliness, self-worth, and behavioural conduct) than children who reported high levels of warmth in both relationships or who experienced high friendship warmth and low maternal warmth. There was a similar pattern for sibling and friend warmth in terms of behavioural conduct such that children who perceived low levels of warmth in both siblings and friendships 
had significantly worse behavioural than children who had high levels of warmth in one or both relationships.

Research also suggests that a secure parent-child attachment is important for children's positive sibling relationships as well as their social competence, whereas insecure attachment predicts both externalizing and internalizing forms of behaviour problems (Booth et al., 1994; Rose-Krasnor et al., 1996; Shamir-Essakow et al., 2005; Teti \& Ablard, 1989; van Brakel, Muris, Bogels, \& Thomassen, 2006).

In contrast, there is much research suggesting that the deferential treatment of siblings by parents can negatively affect the quality of the sibling relationship and the parent-child relationship (Coldwell, Pike, \& Dunn, 2008; Hetherington, 1988; McHale, Crouter, McGuire, \& Updegraff, 1995; Richmond, Stocker \& Rienks, 2005). For example, in a study of parent, child and sibling relationships six years after divorce, Hetherington (1988) reported that parental differential treatment rather than the absolute levels of parental behaviour had the most profound effect on sibling relationships. If one sibling, in comparison to the other, was treated by parents with less warmth and affection and more punitiveness and irritability, that sibling was more likely to behave in a more aggressive and negative manner toward his or her sibling. Furthermore, the more advantageously treated sibling also behaved in a more negative manner toward their sibling. This effect was even more pronounced when both parents favoured the same child.

Research also suggests that not only does the sibling relationship quality deteriorate when parental differential treatment is present but children's concurrent and later socio-emotional adjustment is also affected (Richmond \& Stocker, 2008; Richmond 
et al., 2005; Shanahan, McHale, Crouter, \& Osgood, 2008). Thus, attachment and parentchild relationships in early and middle childhood, especially the differential treatment of children can have profound effects on sibling relationship quality, children's socioadjustment, as well as their peer relations, not only for the child less favoured, but also for both sibling, as well as the family as a whole. McHale, Soli, Groenendyk, and Shanahan (2009) suggest that research concerning sibling relationships challenges research that only looks at one child in the family by showing a more valid and complete picture of adjustment.

Family Structure Variables

Much of the earlier research on siblings has focused on "static" variables such as birth order, age spacing and sex composition. Results from more recent studies have suggested that these factors may play a relatively minor role in sibling's emotional and social development (Brody, 1998; Brody, Stoneman, MacKinnon, \& MacKinnon, 1985, Minnett, Vandell, \& Santrock, 1983. However, research does suggest that these variables can play a role in children's adjustment.

Ordinal positioning/birth order. There is some evidence that younger siblings are more popular and more socially skilled than older siblings (Baydar, Greek, \& BrooksGunn, 1997; Kitzmann, Cohen \& Lockwood, 2002; Miller \& Maruyama, 1976). This may be due to the power differentiation or the hierarchical status difference between firstborn siblings and later-born siblings, which appears to occur universally in childhood and adolescents (Miller \& Maruyama, 1976; Sampson \& Hancock, 1967). Thus, laterborn siblings typically grow up taking a subservient role to their older siblings, who assume a dominant role in sibling interactions (Abramovitch, Corter, \& Lando, 1979; 
Brody, Stoneman, \& MacKinnon, 1982; Furnman \& Buhrmester, 1985; Minnett et al., 1983; Sampson \& Hancock, 1967). Naturalistic observations of sibling interactions indicate that siblings take on asymmetrical, complementary roles when interacting with each other. Older siblings typically act as teachers, managers and helpers, while younger siblings will typically assume the corresponding learner and helper roles (Abramovitch et al., 1986; Brody et al., 1982; Brody et al., 1985). Thus, suggesting that younger siblings may be more influenced by the sibling relationship than vice versa. However, there is some evidence that sibling relationships become more egalitarian during middle childhood (Buhrnester \& Furman, 1991; Vandell, Minnett \& Santrock, 1987), either through an increase in dominance by both siblings (Buhrnester \& Furman, 1991), or an increase in power exerted by the younger sibling (Vandell et al., 1987).

In spite of this, in early childhood, younger siblings may need to develop social skills such as negotiation, accommodation and perspective taking more than their older siblings in order to achieve their fair share of positive outcomes. Indeed this was the case in a study by Miller and Maruyama (1976), who found that younger siblings were more popular in terms of seatmates and play partners than older siblings in three and four children families. Teachers also rated younger siblings as more socially skilled than firstborn; younger siblings were more sociable, friendly, less demanding and less jealous. A comparison with only children revealed similarities between only children and first-born children. Kitzmann and colleagues (2002) also found that second born children were more popular than first-born children. Only children were also less popular and were less accepted by the peer group than second born children with one sibling. However, this study also found that only children were also less popular than first born children with 
one sibling. Only children were also more likely to be both victimized and aggressive in the peer group. In addition, Perner and colleagues (1994) found that first born children with one sibling gave fewer correct responses to false belief questions than second born children with one sibling. Second born children with two siblings also gave fewer correct responses than third born children with two siblings.

Taken together, these results suggest that having a sibling, whether older or younger may provide practice with skills such as the exchange of warmth and support, initiating and maintaining play, perspective-taking, negotiation, compromise and conflict resolution, which all promote social competence in the peer group. However, there may be something inherent in sibling interaction, possibly the asymmetrical roles siblings take on as well as the increased time younger siblings spend in sibling interaction, which may contribute to greater social skills and more popularity for younger siblings and less popularity for older siblings.

Sex composition. Research on the sex composition of sibling dyads suggests that girls are more influenced by their siblings than boys (Sutton-Smith \& Rosenberg, 1970). Older sisters are more likely to assume a caretaker role and be more nurturing and positive with their siblings than older brothers (Abramovich et al., 1979). In a study of 78 year old children, Minnett and colleagues (1983) found that sisters were more likely to praise and teach their sibling while brothers were more likely to engage in neutral or work/play interactions. Same-sex sibling pairs were more likely to engage in cheating, aggression and dominance than mixed-sex pairs.

In contrast, Furman and Buhrmester (1985) found that warmth, closeness, and prosocial behaviour were greater with same-sex siblings than in mixed sex siblings, 
especially when also closer in age. In addition, Cole and Kerns (2001) found that children's perceptions of sibling relationship qualities differed by gender composition, with boy/boy dyads reporting lower levels of positive relationship qualities including caring, intimacy, and conflict resolution than either boy/girl or girl/girl dyads.

Age spacing. Although some research suggests that same-sex siblings close in age (especially girl/girl dyads) have positive sibling relationships (Furman \& Buhrmester, 1985), research concerning age spacing suggests that closely spaced siblings have more conflictual relationships and widely spaced siblings are more nurturing and express more satisfaction in their relationship. Minnett and colleagues (1983) found that 7-8 year olds were more likely to show positive behaviours, affection and high activity with a widely spaced sibling (3-4 years) than with a closely spaced sibling ( $1-2$ years).

Aggression was also more common with a closely spaced sibling. First-born children 3-4 years older than their sibling were more likely to use positive behaviours and teach their sibling as well as to be more dominant than the other groups. Self-deprecation, on the other hand, was greatest in second-born children who were 3-4 years younger than their sibling. Like Minnett and colleagues, Furman and Buhrmester (1985) also found that conflict, quarrelling, antagonism and competition was greatest when siblings were close in age and nurturance with a younger sibling and satisfaction and admiration of an older sibling was greatest when siblings were widely spaced. Widely spaced siblings may experience more nurturance and warmth in their relationship because there may be less need to be competitive when they are at such different levels of development. 
Research results from a growing number of sibling studies suggests that it is not the "static" variables but instead the quality of sibling relationships that is most important for children's socio-emotional functioning (Dunn et al., 1994; Gass, Jenkins, \& Dunn, 2007; Kim, McHale, Crouter, \& Osgood, 2007; Stocker et al., 2002). For example, in a longitudinal study of sibling conflict and adjustment in early adolescence, Stocker and colleagues (2002) found that sibling conflict predicted increases in children's anxiety, depressed mood and delinquent behaviour two years later. Moreover, earlier sibling conflict at Time 1 accounted for unique variance in young adolescents' anxiety, depressed mood, and delinquent behaviour two years later beyond the variance explained by earlier maternal hostility and marital conflict. Earlier adjustment was also not associated with later conflict; thus, supporting the idea that sibling conflict contributes to adjustment over time rather than earlier adjustment problems leadings to later conflict in sibling relationships. Richmond and colleagues (2005) also reported that increases in sibling relationship quality over time were linked to declines in depressive symptoms over time for both older and younger siblings.

Similar results were found in a longitudinal study by Kim et al. (2007) studying the linkages between sibling relationship quality and socio-emotional adjustment from middle childhood through adolescence. The results revealed that as sibling intimacy increased and decreased over time, so did youth perceived social competence. Changes in sibling conflict were positively related to changes in depressive symptoms. In addition, declines in sibling conflict were positively related to declines in depressive symptoms but only for girls. Changes in sibling intimacy and conflict explained changes in youth 
adjustment beyond what was accounted for by mother-child and father-child relationships and by family member's individual adjustment.

In one of the few longitudinal studies involving preschool children, Dunn and colleagues (1994) also found associations between the quality of the sibling relationship and later adjustment. Sibling relationships that were low on warmth and intimacy and high on conflict when children were in the preschool years were associated with both internalizing and externalizing problems both concurrently and seven years later, even when the variance in the adjustment measures that was attributable to mothers' current mood was taken into account. Furthermore, in middle childhood, there were links between a lack of friendly behaviour (not conflict) from older siblings and later internalizing problems for the younger siblings but no associations between younger siblings behaviour and older siblings later adjustment, This may suggest that younger siblings are more vulnerable to the lack of affection from older siblings than vice versa.

In summary, the quality of sibling relationships, particularly the presence of sibling conflict and absence of warmth, from early to middle childhood is associated with later externalizing as well as internalizing problems and this may be especially so for younger siblings. Children who grow up in conflictual relationships with their siblings may also develop difficulties in affective perspective taking and emotional regulation, which could contribute to later adjustment problems both in the internalizing and externalizing realms (Stocker et al., 2002). Sibling and Peer Relationships: Models of Risk and Protection

There is some evidence that children may use the sibling relationship as a kind of learning ground in which they develop, practice and improve their social skills and 
strategies for social interactions, particularly with peers (MacDonald \& Parke, 1984). As noted earlier, children may acquire social and cognitive skills such as affective perspective-taking, emotional understanding, prosocial behaviours and conflict resolution at least in part from their interactions with their siblings (i.e., Dunn \& Munn, 1986; Howe, 1991; Howe \& Ross, 1990; Perner et al., 1994; Youngblade \& Dunn, 1995). We have also seen that the quality of the sibling relationship is related to both internalizing and externalizing adjustment (i.e., Kim et al., 2007; Stocker et al., 2002). Since sibling and peer relationships are similar in many ways (reciprocal and egalitarian relationships, at least more than parent-child relationships), the sibling relationship may be an important context to study in promoting healthy peer relationships.

It is important to distinguish between peer relations and friendship, as there may be different influences between sibling and peer relations and sibling relations and friendship. Peer relations refer to the child's level of acceptance within a group of children, whereas friendship refers to the exclusive relationship between two children. Conceptually sibling relationships and friendship may be linked because they are both close reciprocal relationships with one other individual. Like the sibling relationship, friendship quality has also been linked to social adjustment and internalizing problems in childhood (Rubin et al., 2004). The relationship between sibling and peer relationships is more complex, suggesting that other variables such as temperament and parent-child relationships may also contribute to the association (Lockwood et al., 2001).

Relationships with siblings, peers and friends are assumed to have reciprocal influences; however the nature of the influences is still unclear. There are two explanatory models that are prevalent in the current literature: the carryover model and 
the compensation model. The carryover model predicts similarity in sibling and peer relationships by suggesting that children use the same interaction strategies in multiple types of relationships (i.e., sibling, peer and parent-child relationships). There is also evidence that the influences between these relationships may be bi-directional such that becoming a good sibling may depend, in part, on skills learned through peer interaction and vice versa (Kramer \& Gottman, 1992).

In contrast, the compensation model predicts dissimilarity in sibling and peer relationship quality by suggesting that children may compensate for an unsatisfactory relationship in one area by putting more time and effort into a relationship in another area (Lockwood et al., 2001). For example, if children experience poor peer relationships at school, they may compensate for this through a supportive and warm relationship with a sibling at home and vice versa. However the support received through either the sibling or peer relationship may still protect against negative socio-emotional adjustment such as loneliness and negative self-perceptions. Possible explanations for the discrepancies between findings may be due to developmental factors, differences in informants (i.e., self, parent or teacher), differences in relationship measurements, or factors not measured in the study such as temperament, birth order or sex composition of the sibling dyad.

Support for the carryover model. Several studies provide support for the idea that the effects of a positive or negative sibling relationship may carryover to peer relationships at school. For example, Lockwood and colleagues (2001) found that sibling warmth was associated with positive peer relations, greater social competence and less loneliness. Similarly, in a study of aggressive children, Stormshak and colleagues (1996) found that sibling relationships characterized by high warmth were associated with 
positive teacher rating of social competence and emotional control. In contrast, high conflict was associated with aggressive social difficulties with peers, poor peer relations, and behavioural problems at school. When levels of conflict and warmth were both considered children in involved sibling relationships (moderate conflict and moderate warmth) were rated by teachers as having more emotional control and social competence than children in conflictual relationships (high conflict, low warmth).

In a study of sibling relationships after divorce, Hetherington (1988) also found that a balance of warmth and conflict (companionate-caring; high warmth, moderately low aggression and rivalry) was associated with the best outcomes compared to sibling relationships characterized by high warmth and very low conflict (enmeshed) and relationships characterized by high conflict and moderate warmth (ambivalent). Children in companionate-caring relationships had more positive peer relations, higher academic achievement, more positive self-concepts and lower rates of externalizing and other behaviour problems compared to the other two groups. As we have seen earlier, the results of these studies suggests that conflict may not be a negative factor when combined with moderate levels of warmth but may help children, particularly aggressive children, develop conflict resolution skills.

Mendelson and colleagues (1994) found support for the carryover model in terms of peer popularity but not for friendship. Popular kindergartners tended to feel more positively about their sibling relationship, identify more with their sibling and report higher companionship (if older sibling) than less popular kindergarteners. In contrast, support for the compensation model was found for friendship. These results suggest different mechanisms and influences between sibling and peer relations and sibling 
relations and friendship. Perhaps positive feelings for and identification with an older or younger sibling may lead to skills associated with popularity. Identification and positive feelings for a sibling may foster a readiness to like other children and promote the development of skills or attitudes that enhance competence with many different peers.

In contrast, some studies do report associations between sibling relationships and friendship. McCoy, Brody and Stoneman (1994) found that best friend quality was positively related to sibling relationship warmth and negatively to sibling relationship conflict, such that children who reported relatively poor relationships with their best friends experienced more conflict and less warmth in their relationships with their older same-sex siblings. Temperament and parent-child relationships were also linked to friendship quality and sibling relationship quality. These results suggest that sibling relationships and friendship may be linked through a complex network of interactions between temperament, parent-child relationships, sibling relationships and friendship. This study also illustrates the social learning model whereby children learn interaction patterns in their relationships with family members, which are then carried over to their peer relationships.

Support for the compensation model. In contrast to the carryover model, several studies report an inverse relation between the quality of sibling and peer relations. For example, Mendelson and colleagues (1994) found support for the compensation model for the association between sibling relationships and friendship but not for peer relationships. Kindergarteners who highly rated a same-sex friendship or were observed to be friendly with a same-sex friend tended not to feel positively about a same-sex sibling, and if they had an older sibling, the sibling tended to report low companionship. 
In addition, high companionship with an older sibling was associated with relatively poor same-sex friendships.

Volling and colleagues (1997) also found an inverse relationship between sibling relationships and friendship particularly for first-born siblings. When first-born children reported more negative feelings for their friend at five years, they were more likely to cooperate with a sibling at six years. In addition, when mothers reported more friendly relations between their children and a friend at five years, the older children were significantly more likely to report negative feelings for their younger sibling at this time. Stocker and Dunn (1990) found similar results in a study of 5 to 10 year old siblings. Children who were observed to be competitive and controlling with their siblings were reported by their mothers to have more positive friendships than children who showed more positive interactions with their siblings.

These results may suggest that the social and cognitive skills developed through sibling interaction may not be appropriate (i.e., expectation for initiative or too directive) for interacting with same-age friends. The asymmetry of sibling interactions and differences in reciprocity that exist across sibling relationships and friendship suggest that these relationships may make different contributions to children's social and psychological adjustment (Volling et al., 1997). It is also possible that children who experience negative relationships in one domain may simply devote more time and effort to their relationships in another domain that provides emotional support.

This hypothesis was tested by East and Rock (1992), who examined the extent to which isolated and aggressive $6^{\text {th }}$ graders compensate for unsatisfactory peer relationships through support from siblings and non-school friends. They also explored 
the degree to which this support protected these socially "at risk" children from poor socio-emotional outcomes. Both isolated (may include shy/withdrawn as well as rejected children) and aggressive children are poorly accepted by their peers and are often excluded from normal patterns of interaction (Rubin, Chen, \& Hymel, 1993). The results confirmed that isolated, compared to average and aggressive children, perceived their school friendships as least supportive and their favourite sibling relationship as most supportive and affectionate. Isolated children were also lonelier, had lower selfperceptions of sociability and leadership and were more anxious compared to aggressive and average children. High support from a favourite sibling was associated with better adjustment for isolated children in terms of anxious behaviour and immaturity. Despite the protective role of siblings for isolated children with high sibling support, these children were still less well adjusted than average children.

These results suggest that children who typically have problematic peer relationships (i.e. isolated, aggressive) may compensate for this through a positive sibling relationship but that this does not fully buffer them against adjustment problems. However, to date this hypothesis has not been explored with regards to shy children, who also typically experience poor peer relationships.

\section{Shyness in Early Childhood}

Shyness can be defined as the disposition to be wary and fearful when encountering novel, unfamiliar and/or familiar social situations and/or self-conscious behaviour in situations of perceived social evaluation (Asendorpf, 1991; Cheek \& Busch, 1981; Crozier, 1995; Rubin \& Asendorpf, 1993). The concept of shyness includes behavioural, somatic and cognitive components (Prakash \& Coplan, 2003). Shy children 
have been observed to rarely initiate contact with peers, take longer than typical children to initiate conversations, and speak less frequently than their non-shy peers (Asendorpf \& Meier, 1993; Coplan, Arbeau, \& Armer, 2008; Crozier \& Perkins, 2002; Evans, 2001). In young children, shyness may take the form of reticence or 'hovering' behaviour in social situations (Coplan, Rubin, Calkins, \& Stewart, 1994). Shy individuals may also experience somatic 'stress responses' such as changes in automatic nervous system activity and increases in salivary cortisol levels in response to novelty (Kagan, Reznick \& Snidman, 1987; Kagan, Snidman, \& Arcus, 1993; Spangler \& Schieche, 1998). Cognitively it has been found that shy individuals have greater a greater frequency of negative self-thoughts and self-perceptions of social skills during social interactions (Bruch, Hamer \& Heimberg, 1995; Nelson, Rubin, \& Fox, 2005).

Shyness is part of the larger concept of social withdrawal, which includes the constructs of behavioural inhibition, anxious-solitude, social isolation, social reticence. All of these terms refer to the behavioural expression of solitude although the underlying motivations may differ (Rubin \& Coplan, 2004). Social isolation or active isolation refers to the process whereby children spend time alone in social situations because their peers actively reject and isolate them (Rubin \& Mills, 1998; Rubin et al., 2006). In contrast behavioural inhibition and anxious-solitude refer to the child isolating themselves from the peer group because of internal forces such as anxiety, negative self-esteem, and selfperceived social difficulties (Rubin \& Asendorpf, 1993; Rubin et al., 2002a).

Social reticence describes the behaviour of watching others from afar, remaining unoccupied in the company of peers, and hovering near but not engaging others in interaction (Coplan et al., 1994, Rubin, Coplan, Bowker, \& Menzer, in press). This 
behaviour is typical of shy children who are thought to suffer from an approachavoidance conflict. These children may be motivated to approach others and engage in social interaction (seen through hovering behaviour), but their anxiety and social fear prevent them from completing these behaviours and giving rise to the simultaneous motivation to avoid peer interaction. This type of shyness has been referred to as conflicted- shyness (Asendorpf, 1990; Coplan et al., 2004). Anxious-solitude has also been used to describe wariness in familiar peer contexts (Gazelle \& Ladd, 2003; Gazelle \& Rudolph, 2004).

Shyness is thought to be the behavioural expression of the temperamental trait of behavioural inhibition. Temperament is usually studied with infants and young children and refers to biologically based characteristics that are thought to be present at birth and persist relatively unchanged across the lifetime (Bishop, Spence, \& McDonald, 2003; Rothbart \& Bates, 1998). These characteristics include differences in emotional and physiological reactivity and regulation processes that are expressed through children's negative and positive emotionality, activity level, and sociability (Buss \& Plomin, 1984; Rothbart \& Bates, 1998). Behavioural inhibition refers to the consistent display of wariness and fearfulness when exposed to novel people, things and places (Bishop et al., 2003; Rubin, Burgess, \& Coplan, 2002). Inhibited children typically respond to novel situations with initial restraint, caution, low rates of approach, and quiet withdrawal, and with unfamiliar people they are usually shy, timid, and reticent (Garcia Coll, Kagan, \& Reznick, 1984).

An inhibited temperament may set the course for extreme shyness and inhibition in childhood, adolescence and adulthood; however, this is not always the case. Not all 
inhibited infants become inhibited children and adolescents and this may be due in part to protective factors such as positive parenting, high quality friendships, constructive coping skills, and possibly high quality sibling relationships. The development of extreme shyness is thought to involve the interaction between biology, environment and behaviour in a transactional cycle (Rubin et al., in press).

\section{Biological Expression}

Research suggests that shyness has a substantial inherited component. Plomin and Daniels (1986) reviewed 18 twin studies and found that without exception, MZ twins had significantly higher correlations on measures of shyness than DZ twins. In the infant and child studies reviewed, parental shyness was associated with the child's display of reticence behaviour and distress when exposed to novel situations involving peer and adult strangers. There is also evidence that inhibition and shyness may be linked to physiological differences, such as the excitability of the amygdale, hypothalamus, sympathetic nervous system, EEG activity and salivary cortisol levels (Henderson, Marshall, Fox, \& Rubin, 2004; Kagan et al., 1987; Kagan et al., 1993; Schmidt, 1999).

For example, Kagan and colleagues (Kagan et al., 1987; Kagan et al., 1993) have demonstrated not only the stability of wary, fearful behaviour from two years to six years of age but also the stability of a physiological component to inhibition. Kagan found inhibited children to have increased activity of the limbic area, especially the amygdale and the hypothalamus. Inhibited children also displayed higher and more stable heart rates, higher morning salivary cortisol levels (a stress hormone), and less variability in the pitch of vocal utterances than their more sociable peers. Kagan suggests that the threshold of responsivity to unfamiliarity and challenge in limbic and hypothalamic 
structures may be chronically lower for inhibited as opposed to uninhibited children. Since inhibited children are chronically under stress, social situations may put their level of arousal over the level they can cope with, and thus they may withdraw from these situations. In more recent research, Spangler and Schieche (1998) also found a link between elevated cortisol and the demonstration of behavioural inhibition in early childhood. These physiological indices are characteristic of the fear response seen in both animals and humans (Nadar \& LeDoux, 1999).

Researchers have also established evidence for the display of greater relative right frontal EEG activity in inhibited children and adults (Fox, Henderson, Marshall, Nichols, \& Ghera, 2005; Henderson et al., 2004; McManis, Kagan, Snidman, \& Woodward, 2002; Schmidt, 1999). Infants exhibiting right frontal EEG asymmetries are more likely to cry to maternal separation, and display signs of negative affect and fear of novelty that indicate an inhibited temperament (Davidson \& Fox, 1989; Fox, Bell, \& Jones, 1992). Research suggests that the right frontal region is involved in the experience of negative emotions such as fear and disgust, which facilitates and maintains avoidance behaviours. In contrast, the left frontal region is thought to be involved in the experience of positive emotions such as joy, interest and happiness, which facilitates and maintains approach behaviours (Schmidt, 1999; Schmidt \& Fox, 1999).

In summary, evidence suggests that there is a biological component to shyness from early to late childhood, particularly a low threshold of arousal, and this is especially true for those children who display a temperament high in emotional reactivity and fearfulness when encountering unfamiliar people and events (Fox, Henderson, Rubin, Calkins, \& Schmidt, 2001; McManis et al., 2002). 


\section{Environmental Influences}

Attachment. According to attachment theory reviewed in an earlier section, secure attachment may predict social competence whereas insecure attachments may predict both externalizing (aggression) and internalizing (withdrawal, loneliness, anxiety) problems (Shamir-Essakow et al., 2005). Inhibition has been associated with an insecure parent-child attachment ("C"'-status, ambivalent attachment) in a number of studies (Calkins \& Fox, 1992; Erickson, Sroufe, \& Egeland, 1985; Renken, Egeland, Marvinney, Sroufe, \& Mangelsdorf, 1989; Shulman, Elicker, \& Stoufe, 1994). According to Bowlby's (1973) construct of "internal working models," an insure attachment is characterized by an insecure internal working model of social relationships, whereby the caregiver is depicted as unresponsive and neglectful or over-controlling. Social relationships are viewed as unpredictable, comfortless and unresponsive, causing the child to attempt to avoid rejection through passive, adult-dependent and withdrawn behaviours (Rubin \& Burgess, 2001; Rubin et al., 2002a).

Parenting. Shy children's relationships with significant others, such as their parents or friends, may help to shed light on the relationships shy children may have with their siblings. Parenting practices, varying in involvement, warmth and directiveness, have also been linked to children's later social outcomes (e.g., Booth et al., 1994; McFadyen-Ketchum, Bates, Dodge, \& Pettit, 1996). Mothers of insecurely attached infants have been found to be over-involved and over-controlling when compared to mothers of securely attached infants (Erickson et al., 1985). This over-controlling, intrusive, and overly protective parenting style has been associated with inhibition in a number of studies (e.g., Coplan et al., 2004; Hastings \& Rubin, 1999; Mills \& Rubin, 
1990; Rubin \& Burgess, 2001; Rubin, Burgess, \& Hastings, 2002; Rubin, Nelson, Hastings, \& Asendorpf, 1999) and a number of clinical studies have linked social anxiety, of which withdrawal is a behavioural indicator, to overprotective intrusive parenting (Hudson \& Rapee, 2001; Manassis \& Bradley, 1994). Parents may direct the child's behaviour or take over the responsibility of managing their child's social life, while discouraging their child's independence and social competence (Rubin et al., 2002b). For example, Coplan and colleagues (2004) found that shyness was significantly and negatively related to maternal authoritative parenting and positively to overprotective parenting. Authoritative parenting has been associated with sociability and social competence, whereas parents lower in authoritative qualities are less likely to be positively involved and engaged with their children (Baumrind, 1991; Dekovic \& Janssens, 1992). However, the relation between overprotection and shyness was particularly strong for boys. Mothers may respond to their son's shyness more than their daughters' because the shy behaviour of boys may be more deviant and salient compared to their peers. Moreover, in a clinical sample of anxious and oppositional defiant children, Hudson and Rapee (2001) found that mothers of anxious and oppositional children displayed greater and more intrusive involvement than mothers of non-clinical children. Mothers of anxious children were also more negative during interactions than mothers of non-clinical children.

Hastings and colleagues (Hastings \& Rubin, 1999; Rubin et al., 1999) have also suggested that the relations between shyness and an over-involved and overprotective parenting style may be reciprocal in nature. Thus, not only do parenting strategies and beliefs pertaining to social development affect the child's behaviour but the child's 
behaviour and characteristics may also affect the way the parent will react to the child. Hastings and Rubin (1999) found that mothers reported that they would use more power assertion and structuring to deal with an aggressive child, whereas, in dealing with a withdrawn child they reported they would use warm, supportive and protective behaviours, especially toward their female children.

Rubin and colleagues (1999) also found that parent's perceptions of their toddlers' social wariness and shyness predicted their preference for socialization strategies at age four that limited the inhibited child's independence. These constraints imposed by parents may deny inhibited children with the necessary challenges to develop their own self-regulatory abilities and exacerbate the child's inhibited tendencies.

In support of the environmental component to shyness, Fox and colleagues (2001) found that inhibited children who were placed in non-parental care situations during the first two years of life were more likely to change their behaviour than were similarly inhibited infants who remained in the exclusive care of their parents. In addition, Plomin and colleagues have reported associations between mother and infant shyness not only in non-adoptive homes in which both genetics and family environment are shared, but also in adoptive homes, in which family environment but not heredity are shared (Daniels \& Plomin, 1985; Plomin \& Daniels, 1986; Plomin \& DeFries, 1983). Thus, in accordance with social learning theory, inhibited children may be modeling their parent's socially anxious and withdrawn behaviours and when placed into another setting they may model the anxious or more social behaviour of their new caregivers. In relation to behaviour changes, it is possible that when children are placed in non-parental care they may 
experience more exposure to novel experiences and more interaction with people outside the immediate family, which may lead to more sociable behaviour.

Role of significant others. As the primary social partners of infants, toddlers, and many preschoolers, the quality of parent-child attachment and relationships may greatly influence children's social and cognitive development (Hastings \& Rubin, 1999). This may be especially true of shy children whose relationships with significant others have great influences on their socio-emotional adjustment. For children who are inhibited and experience difficulty regulating their arousal levels, a secure attachment with their primary caregiver and the knowledge that they can depend on them for security in times of stress may be particularly important to their later adjustment (Calkins \& Fox, 1992).

There is also evidence that although shyness places a child at risk for adjustment problems of an internalizing nature, involvement in a good-quality best friendship may help to offset such outcomes by providing experiences that validate self-worth (Fordham and Stevenson-Hinde, 1999). Since the sibling relationship is similar to friendship in many ways (i.e., dyadic and reciprocal) and also offers a safe and familiar environment, conceptually this relationship should benefit shy children's emotional adjustment in comparable ways. However, it is unclear whether the social skills learned through the sibling relationship will transfer to their friendships or whether there will be a compensatory affect.

There have been no reported differences in the quantity of friends or friendship stability for shy children relative to non-shy children (Wojslawowicz, Burgess, RoseKrasnor, \& Booth, 2002). Shy children and young adolescents are just as likely as their peers to have at least one mutual and stable best friend (e.g., Ladd \& Burgess, 1999; 
Rubin, Wojslawowicz, Rose-Krasnor, Booth-LaForce, \& Burgess, 2006; Schneider, 1999). However, differences have been found in terms of friendship quality. For example, Schneider (1999) found that withdrawn children were found to be less communicative with their best friends than non-withdrawn children. In addition, Wojslawowicz and colleagues (2002) found withdrawn children's friendships to be lacking in fun, intimacy, helpfulness and guidance, and validation and caring. Moreover, the best friendships of extremely withdrawn children and young adolescents are more likely to be socially withdrawn and victimized than the mutual best friends of non-withdrawn children (Rubin et al., 2006). Thus, the benefits of friendship for shy-withdrawn children, in terms of their social and emotional adjustment, may be diminished compared to the friendships of nonwithdrawn children.

Shyness and Socio-Emotional Adjustment

This thesis research explored a number of socio-emotional outcomes that have previously been linked to shyness in early childhood, including peer exclusion and withdrawal, anxiety, loneliness, and negative self-perceptions (Cassidy \& Asher, 1992; Coplan et al., 2004; Fordham \& Stevenson-Hinde, 1999; Gazelle \& Ladd, 2003; Ladd, 2006; Rubin \& Mills, 1988). However, in this research, the sibling relationship was proposed as a protective factor for shy children against some of these negative socioemotional outcomes.

Peer exclusion and withdrawal. In recent research, a body of knowledge is accumulating that suggests that the quantity and quality of peer interaction during the early and middle years of childhood have an impact on children's concurrent and later social development (Rubin, Coplan, Chen, Buskirk \& Wojslawowicz, 2005). It is 
therefore important to consider the developmental consequences of those who lack peer interaction. Since shy children have been observed to rarely initiate contact with peers and tend to engage in reticent behaviour typical of the approach-avoidance conflict (the prolonged watching of other children without accompanying play), shy children are thought to lack peer interaction (Coplan et al., 2008; Coplan et al., 2004). In addition, there is strong empirical support linking adult-rated shyness and observed behavioural inhibition with observed social reticence with both unfamiliar and familiar peers in the laboratory and at school (Coplan et al., 2004; Degnan, Henderson, Fox, \& Rubin, 2008; Fox et al., 2005).

There is also evidence to suggest that when shy children do attempt to initiate contact with their peers, they are more likely than their more sociable counterparts to experience peer rejection and exclusion (Gazelle \& Ladd, 2003; Ladd, 2006; Nelson et al., 2005; Rubin \& Krasnor, 1986; Stewart \& Rubin, 1995). Research also suggests that shyness becomes increasingly associated with rejection in middle childhood when the withdrawal and reticent behaviour of shy children becomes increasingly noticeable to the peer group (Bukowski, 1990; Younger \& Boyko, 1987; Younger, Gentile, \& Burgess, 1993).

In support of this, Harrist, Zaia, Bates, Dodge and Pettit (1997) reported that shyanxious kindergarten children were not more sociometrically rejected than their nonwithdrawn counterparts. However, recently a link has been found between shyness and rejection as early as early childhood (Coplan et al., 2004; Hart et al., 2000; Phillipsen, Bridges, McLemore, \& Saponaro, 1999). For example, Phillipsen and colleagues (1999) demonstrated a negative association between shyness and teacher ratings of peer 
acceptance in kindergarteners. Coplan and colleagues (2004) also found a link between conflicted-shyness and teacher-rated peer exclusion in a sample of preschool children but only for boys, adding to the growing literature that shyness may be a greater risk factor for boys than for girls.

When interacting with peers, shy children have also been observed to be less socially competent than non-shy children (Bohlin, Hagekull, \& Anderson, 2005; Nelson et al., 2005; Rubin \& Krasnor, 1986). Rubin \& Rose-Krasnor (1992) defined social competence as the ability to achieve personal goals in social interaction while simultaneously maintaining positive relationships with others over time \& across situations. Socially withdrawn children tend to react to negative social situations with fear and anxiety and this emotional reaction leads to problems in the enacting their social needs and goals, such as using an unassertive, submissive and avoidant social problem solving style (Lemerise \& Arsenio, 2000). For example, in an observational study, Stewart and Rubin (1995) found that socially withdrawn children initiated fewer social contacts, used fewer socially assertive strategies, made fewer requests and were less successful in their attempts. They were also observed to pursue "safer" more lower-cost goals (e.g., "Could you look at this?") and fewer high-cost social goals (e.g., "Can I play with you?"). Because shy children are less successful in their attempts, this reinforces their social schema that the social world is negative and fear-inducing (Rubin, Bowker, \& Gazelle, in press).

Anxiety. Several studies have linked shyness to anxiety and anxiety disorders such as social phobia both concurrently and in later childhood and adolescence (e.g. Burgess et al., 2005; Coplan et al., 2004; Crozier \& Alden, 2005; Findley \& Coplan, 2008; Prior, 
Smart, Sanson \& Oberklaid, 2000; Schwartz, Snidman, \& Kagan, 1999). For example, Coplan and colleagues (Coplan et al., 2004; Findley \& Coplan, 2008) have found links between anxiety and shyness in early as well as middle childhood suggesting that shy children may be suffering from anxiety induced avoidance motivations in social situations (Asendorpf, 1991).

In addition, Prior and colleagues (2000) as part of the Australian Temperament Project reported that 42 percent of children rated as highly shy on six occasions from early childhood to early adolescence also reported anxiety problems in adolescence, compared to 11 percent of children who were never rated as shy. Others studies have also found a link between extreme inhibition in childhood and an increased risk for developing anxiety disorders in adolescents (e.g. Hayward, Killen, Kraemer, \& Taylor, 1998; Schwartz et al., 1999).

Loneliness. Loneliness is the perceived absence of satisfying social relationships and represents subjective feelings of dissatisfaction with current interpersonal relationships, which are often unpleasant and distressing (Peplau \& Perlman, 1982). Conceptually, a link between shyness and loneliness would be expected since shy children are motivated to affiliate with others but are hindered by anxiety in social situations. A number of studies have consistently found links between shyness and loneliness (Asher, Hymel \& Renshaw, 1984; Cheek \& Brusch, 1981; Coplan, Closson, \& Arbeau, 2007; Hymel et al., 1990; Jones, Rose, \& Russell, 1990; Moore \& Schultz, 1983; Rubin, Hymel, \& Mills, 1989; Rubin \& Mills, 1988).

For example, Asher and colleagues (Asher et al., 1984; Cassidy and Asher, 1982) found that loneliness was associated with shyness from early childhood to early 
adolescence. In addition, using data from the Waterloo Longitudinal Project, Rubin and colleagues (Hymel, Rubin, Rowden, \& LeMare, 1990; Rubin et al., 1989) reported that peer assessments and observed social withdrawal in the second grade as well as second grade teacher perceptions of anxious, fearful and solitary behaviours were significant predictors of negative social self-perceptions and loneliness in the fifth grade. Social withdrawal at seven years also predicted loneliness, depression, and negative self-regard at 14 years (Rubin, Chen, McDougall, Bowker, \& McKinnon, 1995).

Finally, there is some evidence from longitudinal studies that shyness precedes and more strongly predicts subsequent loneliness than vice versa (Check \& Brusch, 1981; Goswick \& Jones, 1981). Whether shyness translates into loneliness for a particular individual may depend on the individual's desired level of social interaction (Jones et al., 1990).

Self-Perceptions. Evidence suggests that shy withdrawn children use an internal attribution style whereby their social failures are blamed on stable, personal, and dispositional characteristics rather than on external events or circumstances (Rubin \& Krasnor, 1986; Wichmann, Coplan, \& Daniels, 2004). Shy children have also been found to have negative self-perceptions of themselves in the domains of academic, athletic and social competencies as well as their physical appearance. For example, Hymel and colleagues (1993) found that although socially withdrawn children were viewed by their peers as getting along well with teacher, behaving well in school, academically competent, and as cooperative with peers as average children, they were still viewed by their peers as less socially and athletically competent, and less attractive than average children. Furthermore, withdrawn children expressed more accurate, but negative self- 
evaluations and had significantly lower self-concepts than both average and aggressive children.

In addition, Fordham and Stevenson-Hinde (1999) reported that shyness was highly stable during middle childhood and became increasingly associated over time with internalizing problems such as anxiety, loneliness, and negative perceptions of social acceptance and classmate support. In addition, research indicates that it is the combination of social withdrawal and peer rejection, exclusion and/or victimization that is the strongest predictor of negative outcomes (Boivin \& Hymel, 1997; Gazelle \& Ladd, 2003; Gazelle \& Rudolph, 2004). These findings suggest that it is the negative response of the peer group to shy children's withdrawn behaviour that may cause shy children to internalize negative thoughts and feelings, which may in turn lead them to further withdraw and escape from the peer group in a self-reinforcing cycle (Rubin et al., in press).

Shyness and Sibling Relationships

Research examining the quality of sibling relationships in relation to shy children's adjustment is limited. In fact, there has only been one study to date, examining the protective role of siblings for "isolated" children. As noted earlier, East and Rook (1992) found that while the quality of the sibling relationship partially compensated for isolated children's socio-emotional outcomes, these children were still less socially adjusted than normal children. However, this group of children may include children who have isolated themselves (e.g., shy or socially disinterested children), as well as children who have been isolated from the peer group (e.g., excluded or rejected children). Therefore, it is not clear whether the results will be comparable for shy children. 
Furman, Rahe \& Hartup, (1979) have also found that socialisation with younger children as opposed to same age peers was particularly beneficial for shy-isolated children. Isolated children paired with younger peers showed increases in reinforcing and neutral acts compared to control children at post-treatment and interaction rates did not differ from interaction rates of the general preschool population at post-treatment. These finding suggest that there are unique consequences for mixed-age socialization (i.e., the sibling relationship) as opposed to interaction with same-age peers.

In relation to the literature on shyness and social "surrogates" (Arbeau \& Coplan, 2009; Bradshaw, 1998), it is possible that shy children may use their sibling as a form of social surrogate in social situations (i.e., facilitating social interactions by talking for them, keeping conversations going or introducing them to new people). Although, Bradshaw (1998) did find that the use of social surrogates reduced anxiety for shy children and increased their participation in social situations, the relationship may become detrimental when a dependent relationship is formed. When a healthy sibling relationship is formed, the socio-cognitive, conflict resolution skills as well as prosocial behaviours learned in sibling interaction (Howe \& Ross, 1990; Vandell \& Wilson, 1987), may translate to more positive peer relationships at daycare or preschool. In light of the lack of research in this area, and the importance of significant others for shy children, research examining the potential socio-emotional benefits of the sibling relationship for shy children will be valuable for clinical as well as intervention strategies.

There is, however, some research evidence to suggest that children's temperament will affect their sibling relationships as well as other family and peer relationships (Brody et al., 1987; Brody, Stoneman, \& McCoy, 1994; Munn \& Dunn, 1989; Stocker, Dunn, \& 
Plomin, 1989). For example, Munn and Dunn (1989) reported that in families in which the older sibling was rated as negative in mood, non-adaptable, and non-distractible, sibling pairs engaged less often in joint pretend play. For both the siblings, low distractibility, and for the younger child, high threshold of arousal was associated with high levels of joint pretend play. The amount of conflict between the siblings was also significantly related to each child's temperament. Conflict between siblings was also related to differences in temperament between the two siblings suggesting that the degree of "fit" between the siblings in terms of temperament may affect the quality of the relationship and therefore the potential socio-emotional benefits of the relationship.

Brody and colleagues (Brody et al., 1987; Brody et al., 1994) reported similar results when examining sibling relationships in middle childhood. Findings indicated that when both older and younger sisters were high in activity, emotional intensity, and low persistence there was increased agonistic behaviour, whereas high activity and low persistence levels for younger brothers were associated with more agonistic behaviour among brothers. These results also suggest that it is the "fit" or "match" between the siblings which determines the quality of the relationship and that temperament may serve as a protective or buffering function. For example, if a difficult child (highly active) is placed with a less active or persistent child, this may serve to improve the quality of the relationship and reduce the activity of the difficult child.

Finally, in a longitudinal study from middle childhood to early adolescence, McCoy and colleagues (1994) argue that children's temperament, along with the specific interaction patterns they learn through family relationships, will generalize to their friendships and peer relationships. Results indicated that temperament was associated 
with the quality of children's sibling and best friendships five years later, when considered independently. However, when considered in the context of the other factors in the model, there was only an indirect link between temperament and friendship that was mediated by the warmth and conflict of the sibling relationship, suggesting that each child's temperament may affect the sibling relationship, which in turn will affect the quality of their friendships.

\section{The Current Study}

The main goal of this thesis research was to explore the role of siblings in the socio-emotional and peer functioning of preschool children. In particular, the moderating role of sibling relationship quality in the association between shyness and negative socioemotional adjustment outcomes (i.e., peer exclusion, anxious-fearful behaviour, loneliness and negative perceptions of social competence) was explored.

Two aspects of sibling relationships were considered. First, the relative effects of having an older versus younger sibling were explored. Second, the quality of the sibling relationship was taken into consideration. In addition, the effects of each of these variables were explored with regards to its potential moderating role in the associations between shyness and negative adjustment outcomes.

In relation to the literature, it was anticipated that younger siblings would have better peer relationships than older siblings (Bayder et al., 1997; Kitzmann et al., 2002). However, younger and older siblings were not expected to differ with respect to their emotional functioning (i.e. anxiety, loneliness, and negative self-perceptions) since these variables have been more closely linked to sibling relationship quality rather than birth order (Dunn et al., 1994; Stocker et al., 2002). 
It was expected that children with more positive sibling relationships would also have better emotional outcomes (i.e. less anxiety, loneliness and more positive selfperceptions) than children with a poorer sibling relationships (Stocker et al., 2002; Richmond et al., 2005). It was unclear whether there would be a carryover or compensatory effect with respect to peer relationships (Lockwood et al., 2001). However, it was speculated that a carryover effect would be found, whereby children with more positive sibling relationships would also have more positive peer relationships. This hypothesis was in accordance with Bandura's $(1977 ; 1986)$ social cognitive/learning theory, which suggests that children learn social interaction skills through an individual who they have frequent and intense interactions, such as a sibling, and these attitudes and behaviours are thought to then generalize to other relationships such as the peer group. In relation to shyness, it was expected that children whose parents rate them as more shy would also be rated by teachers as having more peer relation difficulties (Gazelle \& Ladd, 2003; Gazelle \& Rudolph, 2004; i.e., more asocial behaviour, more exclusion by peers and less prosocial behaviour), as well as to report more loneliness and more negative perceptions of social and cognitive competence than children rated as less shy (Fordham \& Stevenson-Hinde, 1999; Hymel et al., 1993). Previous research concerning shyness and birth order is inconsistent; with some studies reporting more shyness for only children and older siblings (Asendorpf, 1986; Zimbardo, 1977), other studies reporting no relationship (Bell et al., 1986; Crozier \& Birdsey, 2003), and yet other studies reporting later-borns to be least shy (Bogels, van Oosten, Muris, \& Smulders, 2001; Zuckerman, 1994). Because of this and the strong evidence for a biological and inherited aspect of shyness (Henderson et al., 2004; Kagan et al., 1993; 
Plomin \& Daniels, 1986), there was not expected to be a difference in shyness between younger and older siblings.

It was unclear whether having a younger or older sibling might benefit shy children the most in terms of their peer relations. Research has demonstrated that younger siblings tend to be more socially competent (Kitzmann et al., 2002). However, it was expected that shy children who have a younger sibling as opposed to an older sibling would benefit more from this relationship, because of the more dominant and care-taking role they would theoretically take on (Brody et al., 1982; Furnman et al., 1979; Furnman \& Buhrmester, 1985).

The quality of the sibling relationship was also expected to be particularly important for shy children and was expected to moderate the association between shyness and emotional adjustment (East \& Rook, 1992; Stocker et al., 2002). More specifically, it was expected that a stronger relation between shyness and internalizing outcomes (e.g., anxiety, loneliness, and negative self-perceptions) would be observed among children with less positive sibling relationships. However, it was predicted that this relation would weaken (i.e., protective role) among children with more positive sibling relationships.

Finally, because of the exploratory in nature of this research, the relation between shy children's sibling relationships and their peer relationships remains unclear. However, it was hypothesized that sibling relationship quality would also moderate relations between shyness and peer relations, such that sibling relationship quality would weaken the relations between shyness and poor peer relations. East and Rook (1992) did not report full compensation in terms of the peer relations of isolated children. However, these children were selected because they were already isolated from the peer group, 
whereas, shy children may or may not be experiencing peer problems (Harrist et al., 1997; Coplan et al., 2004). Sibling relationship quality may be one of the reasons why some shy children do not experience peer problems. This moderating effect was also hypothesized because of the research demonstrating the social and cognitive skills children, including shy children, would learn through positive sibling relationships (Howe \& Ross, 1990; Tucker et al., 1999; Vandell \& Wilson, 1987).

Method

\section{Participants}

An original sample of $\mathrm{n}=95$ children was recruited from 12 preschool and daycare centers in the city of Ottawa, Ontario and one daycare centre in the town of Carleton Place, Ontario. The overall consent rate was estimated at approximately $32 \%$. This rate was likely lowered because recruitment was aimed primarily at families with more than one child. Indeed, the parents of only children without siblings $n=11$ provided positive consent. As such, these children were subsequently excluded from the study. As well, there were five instances where both siblings from the same family were included in the study. In order to avoid statistical problems of non-independence, one child from each of these 5 sibling pairs was randomly selected to be the "focal child", whereas the other was excluded from the study.

The final sample included $n=79$ children ( 35 girls, 44 boys) ranging in age from $3.8-6.7$ years $(M=4.74$ years, $S D=.66)$. Sixty-three children had one sibling, 14 had two siblings and 2 had three siblings. Siblings closest in age to target children (44 girls, 35 boys) ranged in age from $.6-17.2$ years $(M=5.15, S D=3.27)$ In terms of sex composition and birth order, 19 dyads were "girl/girl", 19 were "boy/boy" and 41 were 
mixed sex; 39 target children had a younger sibling, 37 had an older sibling, and 3 were twins. Age differences between the focal children and their siblings ranged from 0 (in the case of a twin) to 13.1 years $(M=2.82, S D=1.83$ years $)$.

Seventy-one parents were either married or had a common-law agreement and 8 parents were separated or divorced. Mothers ranged in age from 26 - 48 years $(M=37.4$, $S D=3.99)$, and fathers ranged in age from $31-49$ years $(M=38.9$ years, $S D=4.36)$. In terms of education, $10.1 \%$ of mothers had completed high school, $12.7 \%$ had completed community college, $43.0 \%$ had university degrees, and $34.2 \%$ had obtained a graduate school degree. In regards to fathers, $10.1 \%$ had completed high school, $16.5 \%$ had completed community college, $36.7 \%$ had university degrees, and $32.9 \%$ had obtained a graduate school degree. Concerning ethnicity, mothers were predominately Caucasian (85.3\%), 6.3\% were Asian, 1.3\% were Hispanic, and 5.1\% were of other ethnicities. Fathers were also predominately Caucasian (78.5\%), 6.3\% were Asian, 1.3\% were Black, $2.5 \%$ Hispanic, and $5.1 \%$ were of other ethnicities.

Sixty-eight families reported that English was the primary language spoken at home and 11 families reported that it was not their primary language. In terms of child care experiences, 15 families reported that their most frequent form of child care in the last 2 years was at home with a parent, 12 families reported group homecare, and 52 families reported that a child care centre was their most frequent form of child care.

Procedure

Upon obtaining approval from the Carleton University Psychology Department Ethics Review Board, directors were contacted by phone or email to request permission to conduct the study in their preschool or daycare. They were informed of the purposes of 
the study as well as what was expected of the parents, teachers, and children. Packages were delivered to the preschools/daycares and sent home with the children to obtain parental consent (see Appendix A). Parents who gave consent were asked to complete questionnaires assessing basic Demographic Information, the Child Social Preference Scale, and the parental version of the Quality of Relationship Scale (for parents who have two children).

Target children who had parental consent, and who had a sibling, were then asked to participate in individual interviews (see Appendix B), administered by a trained researcher (primary researcher and two graduate students), that were scheduled at a time that was most convenient for the preschool/daycare teachers. Children were given the opportunity to deny participation if they desire. Two children denied participation in the individual interviews and were omitted from analyses concerning self-perceptions, loneliness, and self-rated sibling relationship quality. The interviews were approximately $10-15$ minutes in length and included the sibling appraisal subscale of the Quality of Relationship Scale, the Loneliness and Social Dissatisfaction Scale for Young Children and the Pictorial Scale of Perceived Competence and Social Acceptance for Young Children. Teacher packages were given to the teachers at the time of the individual interviews and included the Child Behaviour Scale.

Measures

Demographics. Demographic information was collected from parents to assess background information and control variables. Information on parental age, education, ethnicity, marital status, child care, primary language and number of children was 
collected. In addition, child demographic information on both siblings was collected, such as gender and age (see Appendix C).

Shyness. Parents were also be asked to fill out the Child Social Preference Scale (CSPS, Coplan et al., 2004 - see Appendix D). This scale was developed as a parental assessment of child shyness and social disinterest, however only the shyness subscale is of interest for this study. This subscale consists of 7 items rated on a 5-point Likert scale focusing on social motivations and behaviours that are consistent with the "approachavoidance conflict" typical of temperamental shyness (e.g., "My child seems to want to play with other children, but is sometimes nervous to"; "My child often watches other children play without approaching them"; $\alpha=.88$ in the current sample). This subscale has been used in several studies with young children and has demonstrated good psychometric properties $(\alpha=.86-.89)$ as well as consistent associations with other parental assessments of child shyness, teacher ratings of child anxiety, and behavioural observations of children's free play behaviours (Coplan et al., 2008; Coplan \& Armer, 2005; Coplan et al., 2004).

Socio-emotional functioning. Teachers were asked to complete the Child Behavior Scale (CBC, Ladd \& Profilet, 1996 - see Appendix E) to assess children's social competence and behaviour problems at preschool. The scale assesses both positive and problematic child behaviour and competence in six domains, however only four subscales are of interest: prosocial behaviour (7 items, e.g., "helps other children", $\alpha=.88$ ), asocial behaviour (6 items, e.g., "prefers to play alone", $\alpha=.83$ ), anxious-fearful behaviour (4 items, e.g., "appears miserable, unhappy, tearful or distressed", $\alpha=.71$ ) and excluded by peers ( 7 items, e.g., "peers refuse to let child play with them", $\alpha=.88$ ). Teachers rated 
each item on a 3-point Likert scale (i.e., 3 - certainly applies, 2 - applies sometimes and 1- doesn't apply). Subscale item ratings will be averaged to create a single score for each child for each subscale. This scale has been used extensively with preschool, kindergarten and elementary school children (e.g., Booth-LaForce \& Oxford, 2008; Buhs, Ladd, \& Harald, 2006; Coplan et al., 2004; Ladd, 2006; Ladd \& Troop-Gordon, 2003), and the subscales have been shown to be valid and reliable for use with young children ( $\alpha$ $=.88, \alpha=.78-.92, \alpha=.77-.82$, and $\alpha=.86-.95$, respectively).

Self-perceptions. A trained researcher interviewed children individually using the Preschool/Kindergarten version of the Pictorial Scale of Perceived Competence and Social Acceptance for Young Children (PSPCSA; Harter \& Pike, 1984 - see Appendix F) to assess children's perceptions of their social competence and acceptance at preschool. This scale was adapted from the Perceived Competence Scale for Children (Harter, 1982) to be more appropriate for young children. The subscales of interest include, perceived peer acceptance (PPA, 6 items, i.e., "This girl/boy gets asked to play with others/this girl/boy gets lonely sometimes because other kids don't get ask her/him to play", $\alpha=.63$ ) and perceived cognitive competence (PPC, 6 items, i.e., "This girl/boy is pretty good at puzzles/this girl/boy isn't very good at puzzles", $\alpha=.71$ ). Children were presented with two opposing pictures of a child in different social and cognitive situations and will be read an accompanying brief statement for each picture. Children were asked to indicate the child who was most like him or her, and then to indicate, by pointing to the appropriate circle, whether the child is a lot like him/her (big circle) or just a little like him/her (smaller circle). This scale is one of the most commonly cited and extensively employed tools to assess young children's perceptions of their competencies and 
relationships in a variety of research areas including research with shy children (see Byrne, 1996). It has been found to have moderate to good internal consistency ( $\alpha=.72$ .78 and $\alpha=.70-.74$ respectively; Coplan et al., 2008; Coplan, Girardi, Findlay \& Frohlick, 2007; Harrist \& Bradley, 2003; Harter \& Pike, 1984; Ladd \& Troop-Gordon, 2003) as well as convergent, discriminant and predictive validity (Harter \& Pike, 1984). Loneliness. Children were also interviewed individually using the Loneliness and Social Dissatisfaction Scale for Young Children (LSDYC; Cassidy \& Asher, 1992 - see Appendix G). This scale focuses on children's feelings of loneliness, feelings of social adequacy and subjective estimations of peer status. It consists of 16-items rated on a 3point scale (e.g., "Do you have kids to play with at school?", $\alpha=.73$ ). Children were asked to point to the appropriate circle that will represent yes no or sometimes. Cassidy and Asher (1992) recommend this scale for use with children as young as kindergarten and although the children in this study will be one year younger, the items are still appropriate for the preschool setting. Psychometric properties were assessed to determine the validity and reliability of this scale with preschool children. This scale has been used in several studies with kindergarten and first grade children (e.g., Booth-LaForce \& Oxford, 2008; Coplan et al., 2007a; Ladd \& Troop-Gordon, 2003) and has demonstrated excellent psychometric properties $(\alpha=.76-.91)$, consistent factor structure across samples, high internal consistency and good test-retest reliability (e.g., Terrell-Dutch, 1999). Items will be averaged to create an aggregate measure with higher scores indicating more loneliness and social dissatisfaction.

Sibling relationship quality. Children were also interviewed using the Quality of Relationship Scale (QRS, Ross, Woody, Smith, \& Lollis, 2000 - see Appendix H). This 
scale was developed to assess the quality of relationships within the family, however, only child self and other ratings and parent appraisals of the sibling subscale is of interest in the present study (11 items). To complete this measure, children were shown two paper puppets who each represent their sibling (matched for gender and hair colour) and were read two opposing statements, one for each puppet (e.g., "Erin is mean to me" versus "Erin is not mean to me"). Children choose the one that was more like their sibling, and then indicated the degree of similarity (a lot or a little). Children also responded to the same 11 items from their own perspective (e.g., "I am a good brother/sister" versus "I am not a good brother/sister"). The order of presentation for items from the self and sibling perspectives, and for positive versus negative items, was randomized. Item ratings were averaged to create a single score with higher scores indicating a warmer and closer sibling relationship and lower scores indicating a more distant and conflictual relationship, $\alpha=.91$. The sibling appraisal subscale has been used in several studies with preschool and elementary school children (Ram \& Ross, 2001; Ross et al., 2006; Ross, Stein, Trabasso, Woody \& Ross, 2005; Ross et al., 2000) and has been shown to have good psychometric properties ( $\alpha$ 's ranging between .80 and .85 ; test-retest reliability estimates ranging between .50 and .91; Ross et al., 2000).

Parents also rated their children's relationship with their sibling using a parental version of the sibling appraisal subscale. This scale included the same 11 items from both children's perspectives rated on a 4-point Likert scale (e.g., "Erin is nice to Molly" versus "Erin is not nice to Molly", and "Molly is shares with Erin" versus "Molly does not share with Erin", $\alpha=.87$ ). Positive and negative items, as well child perspectives were also randomized. Items were averaged to create a single score for parents' perception of target 
child's relationship with their sibling, with higher scores indicating a more positive sibling relationship. Ross and colleagues (2000) report moderate internal consistency ( $\alpha=$ $.68-.70)$ and test-retest reliabilities estimates (.63 to .82 .).

Results

Analyses were conducted in four stages. The first set of analyses looked for outliers and tested the statistical assumptions. The second set considered descriptive statistics and the correlations between independent, dependent and control variables. The third compared groups of children with a younger versus older sibling in terms of the dependent variables (i.e., socio-emotional outcomes). Finally, hierarchical regression analyses were employed to explore the moderating role of sibling characteristics in the association between shyness and socio-emotional outcomes.

\section{Outliers and Statistical Assumptions}

Data was cleaned and checked for missing values, outliers and influential cases. Very few missing data was present and was dealt with by imputing the individuals' mean value for the particular variable. In terms of outliers, data was checked for outliers on each of the independent and dependent variables by looking at the Studentized Deleted Residuals. Cases with $z$-scores larger than $|3|$ standard deviations were considered to be outliers. Four such cases were found using regression models, shyness x parent-rated sibling relationship quality, shyness $\mathrm{x}$ self-rated sibling relationship quality, and shyness $\mathrm{x}$ birth order (case 24 on the dependent variable perceived cognitive competence (PCC, $z$ $=|3.91|,|3.99|$, and $|4.43|$, respectively), case 42 on the dependent variable asocial behaviour $(z=|4.48|,|4.74|$, and $|4.38|$, respectively), case 26 on the dependent variable anxious-fearful behaviour ( $z=|3.11|,|3.36|$, and $|3.57|$, respectively), and case 44 on the 
dependent variable exclusion by peers $(z=|5.37|,|5.62|$, and $|5.27|$, respectively). Cases 24, 42 and 26 were also found to be influential cases by looking at DFBETA, Leverage and Cook's Distance values in relation to their respected cut-off values, and were adjusted to be within 1 standard deviation unit from the next most extreme case in the distribution (Tabachnick \& Fidell, 2007).

The use of hierarchical regression and ANOVA models implies that five assumptions be met. The first assumption requires a normal distribution of the dependent variables. However, studies with medium to large sample sizes are typically robust to this assumption, meaning that the obtained $\mathrm{F}$ value is fairly accurate. This can be tested by looking at the skewness and kurtosis values, frequency histograms, box-plots, stem and leaf plots, and Q-Q plots and Shapiro-wilk tests. The dependent variables PCC, anxiousfearful behaviour, asocial behaviour, and exclusion by peers displayed non-normal distributions. This was dealt with by removing extreme outliers in the case of $P P C$, asocial behaviour and anxious-fearful behaviour. However, inspection of the exclusion distribution revealed a floor effect, such that $62 \%$ of the sample received a score of 1 out of a possible 3 on the scale. In light of this, this variable was recoded into a categorical variable (i.e., with values of non-excluded vs. excluded).

The second and third assumptions are that of homogeneity of variance (homoscedasticity) and linearity. For ANOVA homogeneity of variance means that the variances in each group of the dependent variable should be approximately equal. For regression, homogeneity of variance means that the residuals should be approximately equal for all predicted dependent variable scores and linearity means that there is a linear relationship between the dependent variable(s) and the independent variable(s). These 
assumptions can be tested by looking at residual scatter plots, for compliance of this assumption, along with independence of errors there should be a concentration of points around the center. The dependent variables of anxious-fearful behaviour, asocial behaviour and exclusion had violations to these assumptions. In the case of asocial behaviour and anxious-fearful behaviour this was dealt with by adjusting extreme outliers and in the case of exclusion, it was recoded into a categorical variable.

The fourth assumption is in regards to independence of errors, which assumes that each case is randomly selected from the population and considered only once. For ANOVA this can be tested using the Durbin Watson statistic with values above 2 indicating a problem with a particular case. For regression, this can be tested by looking at a plot of Studentized Deleted residuals as a function of case number. All dependent variables met this assumption.

The fifth assumption involves multicollinearity. For regression this means that the independent variables should not be highly correlated with each other. This can be assessed by looking at scatter plots, bivariate and partial correlations between the variables, confidence intervals and by using the VIF and tolerance statistics. No independent variables were highly correlated with the dependent variables. Descriptive and Correlational Analyses

Demographic and potential control variables. Correlations between parental and child demographics and each of the independent and dependent variables were computed to determine if these variables might need to be controlled for in subsequent analyses. Overall, demographic variables were largely unrelated to study variables. Maternal education was significantly and positively correlated with parent-rated sibling 
relationship quality $(r=.24, p<.05)$. Child age was significantly and negatively correlated with loneliness $(r=-.30, p<.01)$ and positively correlated with prosocial behaviour $(r=.47, \mathrm{p}<.01) . T$-tests also revealed a significant difference in shyness as function of marital status, $t=-2.00, p<.05$, whereby parents who were separated or divorced rated children as more shy $\left(M_{\text {separated/divorced }}=2.74, S D=.87\right)$ than parents who were married or in a common law relationship $\left(M_{\text {married/common law }}=2.16, S D=.76\right)$. Since no consistent pattern of associations was found, demographic variables were not controlled for in subsequent analyses.

In addition a series of $A N O V A$ and correlational analyses were performed to assess the effects of sex composition and age spacing on the independent and dependent variables. Results revealed a significant relation between sex composition and prosocial behaviour, $F_{2,76}=3.57, p<.05$. Post-Hoc analyses using Tukey HSD revealed that girls with a female sibling were significantly more prosocial $\left(M_{\text {girl } / \text { girl }}=2.52, S D=.41\right)$ than boys with a male sibling $\left(M_{b o y / b o y}=2.13, S D=.45\right)$. No age spacing effects were found. Again, no consistent pattern of correlations was found, and as a result, these variables were not controlled for in subsequent analyses.

Correlations between independent and outcome variables. Self and parent-rated sibling relationship quality were significantly and positively inter-correlated $(r=.24, p<$ .05). Shyness was not significantly correlated with either self-reported $(r=.11, n s)$ or parent-rated $(r=.04, n s)$ sibling relationship quality.

Correlations between shyness, sibling-relationship quality, and indices of socioemotional functioning are displayed in Table 1. For the most part, results were consistent with hypotheses. For example, parent-rated shyness was significantly and positively 
correlated with teacher-rated asocial behaviour and the negative relations between shyness and both perceived cognitive competence and prosocial behaviour approached significance. Thus, children rated as more shy tended to perceive themselves as less cognitively competent and teachers rated them as performing more asocial and less prosocial behaviour at preschool or daycare. Both self and parent-rated sibling relationship quality were significantly and negatively correlated with loneliness but not with other indices of socio-emotional functioning. In other words, children who had better relationships with their sibling were less lonely than children who had less positive sibling relationships. Correlations between outcome variables are presented in Table 2 .

Since peer exclusion was converted to a categorical variable, a series of $t$-tests was conducted to assess the effects of exclusion on each of the independent and dependent variables. As compared to non-excluded counterparts, children rated by teachers as being excluded by peers were also rated by teachers as being significantly more asocial $\left(t=-4.27, p<.001, M_{\text {excluded }}=1.48, S D=.42 ; M_{\text {non-excluded }}=1.13, S D=.22\right)$, more anxious $\left(t=-2.75, p<.01, M_{\text {excluded }}=1.61, S D=.42 ; M_{\text {non-excluded }}=1.36, S D=.39\right)$, and less prosocial $\left(t=2.74, p<.01, M_{\text {excluded }}=2.19, S D=.09 ; M_{\text {non-excluded }}=2.49, S D=\right.$ .06). Excluded and non-excluded children did not differ significantly in terms of shyness $(t=-.55, n s)$, self-reported $(t=.58, n s)$ or parent-rated sibling relationship quality $(t=-$ $1.17, n s)$, perceived competence $(t=-.64, n s)$, perceived acceptance $(t=.13, n s)$, or loneliness $(t=-.58, n s)$.

Effects of birth order. A series of $t$-tests was performed to assess the effects of birth order on shyness, sibling relationship quality and socio-emotional outcomes. The results revealed no significant birth order effects. Thus, children who had a younger 
Table 1

Correlations between Independent Variables and Socio-Emotional Outcome Variables.

\begin{tabular}{lcccccr}
\hline & PCC & PPA & loneliness & anxious & asocial & prosocial \\
\hline Shyness & $-.19+$ & -.10 & .10 & .24 & $.24 *$ & $-.20+$ \\
Parent SRQ & -.07 & .04 & $-.28^{* *}$ & .09 & .11 & .00 \\
Child SRQ & .07 & .13 & $-.38^{* * *}$ & .03 & -.10 & .17 \\
\hline
\end{tabular}

$* * * p<.001 . \quad * * p<.01 . \quad * p<.05 . \quad+p<.10$

PPC - perceived cognitive competence

PPA - perceived peer acceptance

SRQ - sibling relationship quality 
Table 2

Correlations between Socio-Emotional Outcome Variables.

\begin{tabular}{|c|c|c|c|c|c|}
\hline & 2 & 3 & 4 & 5 & 6 \\
\hline 1. PCC & $.36^{* * *}$ & $-.20+$ & .04 & -.02 & $.22 *$ \\
\hline 2. PPA & & -.09 & -.03 & -.07 & .10 \\
\hline 3. Loneliness & & & .14 & .12 & $-.27 *$ \\
\hline 4. Anxious & & & & $.40^{* * *}$ & -.09 \\
\hline 5. Asocial & & & & & -.14 \\
\hline 6. Prosocial & & & & & \\
\hline
\end{tabular}

*** $p<.001 . \quad * p<.05 . \quad+p<.10$.

PPC - perceived cognitive competence

PPA - perceived peer acceptance 
sibling did not differ from children who had an older sibling in terms of shyness $(t=.90$, $n s)$, self $(t=.23, n s)$ or parent-rated $(t=-.21, n s)$ sibling relationship quality, or socioemotional outcomes (perceived competence, $t=.35$, ns, perceived acceptance, $t=-.34$, $n s$, loneliness, $t=.52, n s$, anxious behaviour, $t=.12, n s$, asocial behaviour, $t=-.40, n s$, exclusion, $t=.06, n s$, and prosocial behaviour, $t=.72, n s)$.

Hierarchical Regression Analyses

In order to address the main research question pertaining to the moderating role of sibling characteristics in the associations between shyness and socio-emotional outcomes, a series of hierarchical regression analyses were performed. Two characteristics of siblings were explored as potential moderators: (1) having an older vs. a younger sibling; and (2) the quality of the sibling relationship (as assessed by self-report and parentratings). Separate equations were conducted for each of these sibling characteristics. For example, to explore the moderating role of sibling relationship quality, standardized main effect variables (i.e., shyness, sibling relationship quality) were entered in step one. In step two, two-way interactions terms (i.e., shyness $x$ sibling relationship quality) were entered. The $N$ 's for each analysis vary slightly as a function of missing data (i.e. two children did not complete the individual interview). In order to ease presentation (and since "main effect" correlations between shyness and sibling relationship quality and outcome variables are already displayed in Table 1), only results related to the interaction terms are summarized in Table 3.

To begin with, a significant shyness $x$ parent-rated sibling relationship quality interaction was observed in the prediction of teacher rated anxious-fearful behaviour. Interaction effects were explored using simple slopes analyses (Aiken \& West, 1991). 
Table 3

Results of Hierarchical Regression Analyses Predicting Indices of Adjustment from

Interactions between Shyness, Self and Parent-Rated Sibling Relationship Quality and

Birth Order.

Dependent Variable

Two-Way Interaction terms $\left(s r^{2}\right)$

\begin{tabular}{llll}
\hline & $\begin{array}{l}\text { Shyness x } \\
\text { Parent SRQ }\end{array}$ & $\begin{array}{l}\text { Shyness x } \\
\text { Child SRQ }\end{array}$ & $\begin{array}{l}\text { Shyness x } \\
\text { Birth Order }\end{array}$ \\
PCC & .007 & .000 & .003 \\
PPA & .002 & .014 & .001 \\
Loneliness & .000 & $.073 * *$ & .004 \\
Asocial & .000 & .001 & .024 \\
Anxious & $.057^{*}$ & .000 & .023 \\
Prosocial & .000 & .015 & \\
\hline PPC - perceived competence & & & \\
PPA - perceived acceptance & & & \\
SRQ - sibling relationship quality & &
\end{tabular}


Results are displayed in Figure 1. Decreases in parent-rated sibling relationship quality corresponded with an increased positive association between shyness and teacher-rated anxious-fearful behaviour. In contrast, at increased levels of parent-rated sibling relationship quality there was a negative relation between shyness and teacher-rated anxious-fearful behaviour.

There was also a significant shyness $x$ self-rated sibling relationship quality interaction in the prediction of self-reported loneliness. Results from simple slopes analyses are displayed in Figure 2. A similar pattern was observed. At lower levels of self-rated sibling relationship quality there was an increased positive association between shyness and self-reported loneliness. In contrast, this relation was attenuated at increased levels of self-rated sibling relationship quality. In other words, a closer sibling relationship appears to act as a protective factor for shy children with regards to anxiety and loneliness at daycare or preschool. Finally, no significant shyness $x$ birth order effect interactions were found in the prediction of socio-emotional adjustment outcomes.

Binary logistic regression. Since exclusion was recoded into a categorical variable, binary logistic regression was used to assess the effects of the interaction terms (shyness $x$ parent-rated sibling relationship quality, shyness $x$ self-rated sibling relationship quality, and shyness $x$ birth order) in the prediction of exclusion. Results revealed no significant interaction effects. 
Figure 1. Interactions between Shyness and Parent-Rated SRQ in the Prediction of Teacher-Rated Anxious-Fearful Behaviour.

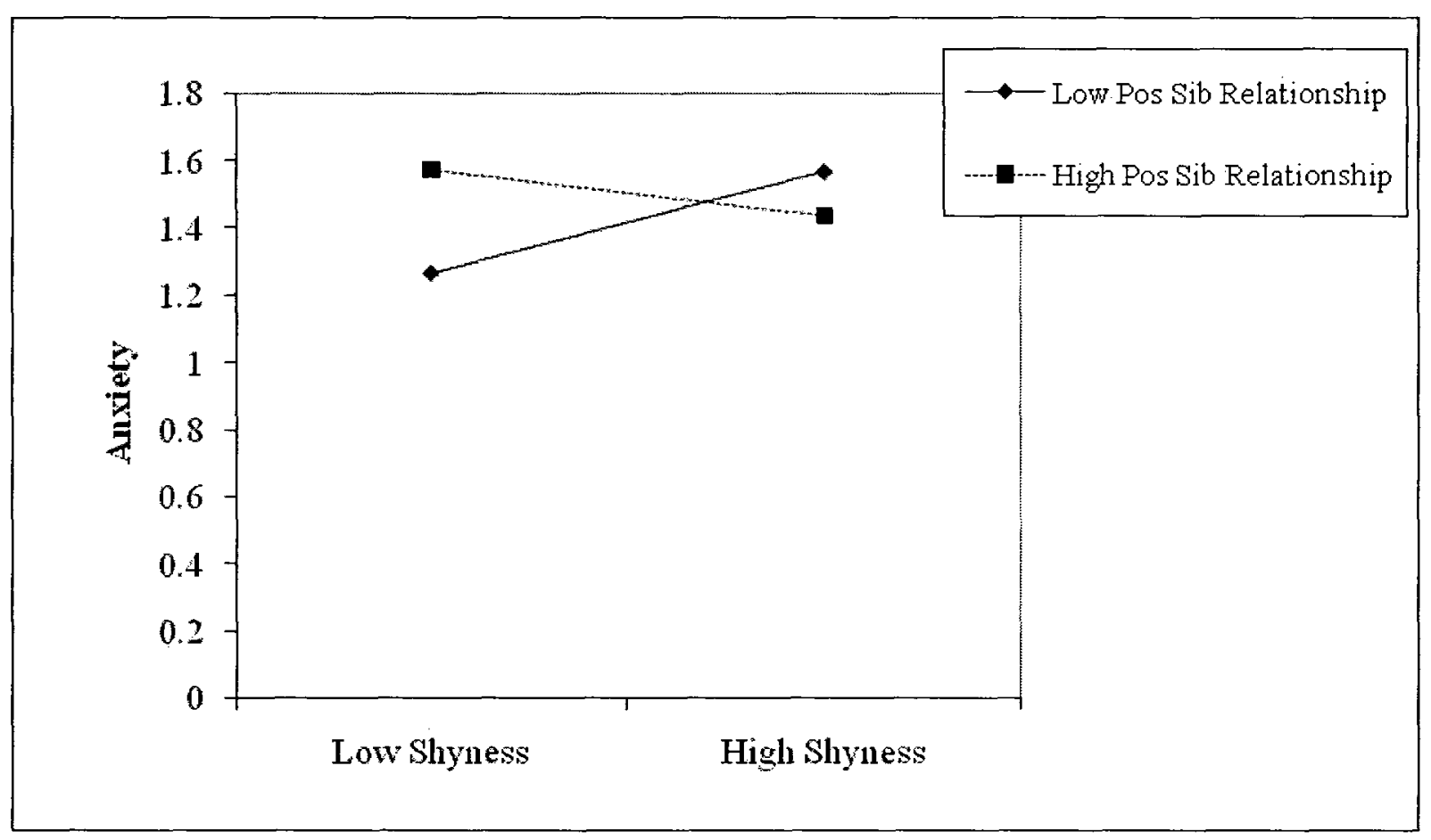


Figure 2. Interactions between Shyness and Self-Rated SRQ in the Prediction of Self-

\section{Rated Loneliness.}

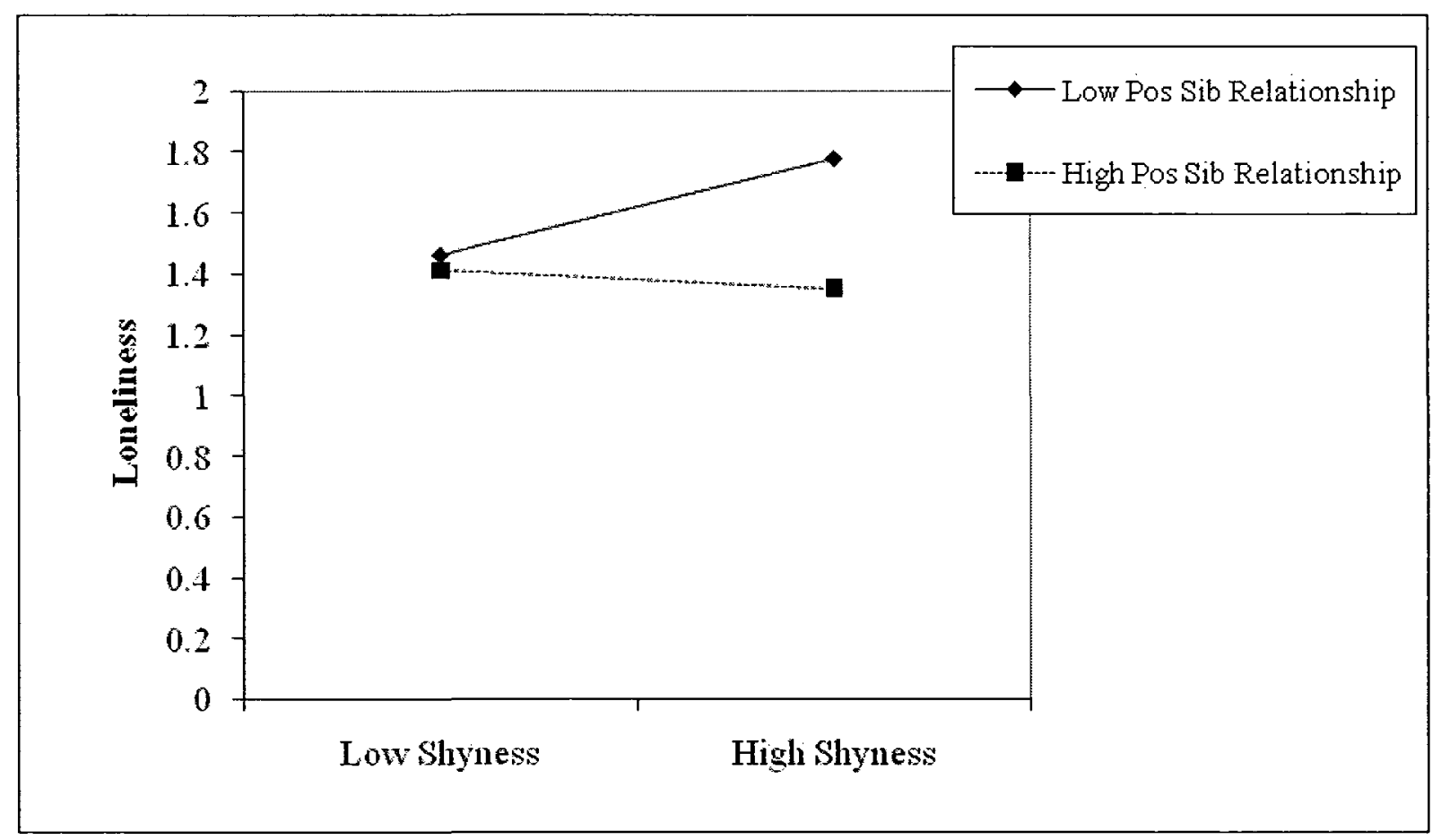




\section{Discussion}

The goal of this thesis research was to examine the protective role of siblings in shy children's socio-emotional functioning. Overall, it was hypothesised that teachers would rate younger siblings as having better peer relationships than older siblings. It was also anticipated that children who had more positive sibling relationships would have better socio-emotional outcomes. Shyness was expected to be negatively related to indices of socio-emotional adjustment. In addition, sibling relationship quality was expected to moderate the association between shyness and negative socio-emotional adjustment. Finally, it was expected that shy children with a younger sibling would benefit more from the relationship in terms of socio-emotional outcomes than shy children with an older sibling.

In general, results indicated that both shyness and sibling relationship quality were associated with adjustment at preschool/daycare. For example, children with closer sibling relationships reported being less lonely at preschool and daycare than children with less positive sibling relationships. In contrast, shyness was related to less positive perceptions of cognitive competence and the display of increased social withdrawal and decreased prosocial behaviours at preschool. In addition, the results suggest that a close sibling relationship might buffer shy children from some negative socio-emotional outcomes, including loneliness and anxious-fearful behaviour at preschool. Family structure variables (age spacing, sex composition, and birth order) were largely unrelated to shyness, sibling relationship quality or indices of socio-emotional functioning. In the following sections, these results are discussed in more detail. 
As expected, parent-rated shyness was significantly associated with indices of maladjustment. Shyness was significantly and positively associated with teacher-rated asocial behaviour and the negative associations between both self-reported perceived competence and teacher-reported prosocial behaviour approached significance. These findings support growing research linking shyness and adjustment difficulties in early and middle childhood (e.g., Coplan et al., 2008; Gazelle \& Ladd, 2003; Hymel et al., 1993). Several studies report associations between shyness and reticent/withdrawn behaviour (i.e. "hovering") in both unfamiliar and familiar settings as early as the preschool age (e.g. Coplan et al., 2008; Degnan et al., 2008). It is suggested that shy children from an approach-avoidance conflict, whereby they are motivated to approach others and engage in social interaction but their anxiety and social fear prevent them from doing so (Coplan et al., 2004). However it is encouraging that shyness was not associated with exclusion in this sample.

It is noteworthy that even at such a young age, shyness is still positively associated with negative self-perceptions of cognitive competence. Generally, the selfperceptions of preschool children have been found to be unrealistically positive (Harter \& Pike, 1984) and it is suggested that this may serve to motivate children toward greater levels of mastery. Thus, it is potentially worrisome that shy children tend to have negative self-perceptions at an age when it is so developmentally "untypical" to do so. Negative self-perceptions in preschool and school-aged children have been found to be correlated with internalizing problems such as loneliness as well as negative peer relations such as social withdrawal, exclusion and rejection (Coplan, Findlay, \& Nelson, 2004; Fordham \& Stevenson-Hinde, 1999, Hymel et al., 1990). Thus, when shy children 
internalize negative thoughts and feelings, they may further withdraw from the peer group in a self-reinforcing cycle.

Prosocial behaviour has also been negatively linked with shyness and social withdrawal and positively linked with sociability and more sophisticated social understanding in previous research (e.g., Findlay, Girardi \& Coplan, 2006; Robinson, Zahn-Waxler, \&Emde 1994; Rubin \& Rose-Krasner, 1992). The literature suggests that prosocial children tend to have well developed perspective-taking abilities and moral reasoning, and do well academically (Miller, Eisenberg, Fabes, \& Shell, 1996; Welsh, Parke, Wideman, \& O'Neil, 2001). As such, prosocial behaviour has been associated with healthy social and emotional functioning including positive peer relations (Eisenberg \& Fabes, 1998). Shy children may be overwhelmed by their emotions and unable to self-regulate and therefore more likely to experience personal distress and have difficulty expressing sympathy towards other children (Findlay et al., 2006). Because shy children perform less prosocial behaviours toward other children, and have a more limited range of social reasoning skills, they may be viewed more negatively or ignored by their peer group leading to further social withdrawal. Indeed, Findlay and colleagues (2006) found that although empathetic children expressed more sympathy for shy children they were not more likely to be that child's friend. Taken together, these results add to the growing literature suggesting long term risks for shy children (Gazelle \& Rudolph, 2004; Prior et al., 2000). These findings highlight the need to identify protective factors, such as the sibling relationship, that may prevent shy children from experiencing negative socio-emotional outcomes throughout the life course. 
Finally, it was interesting to note that shyness was unrelated to sibling relationship quality. It was speculated that shy children might have better relationships with their siblings because of their peer relation difficulties (Coplan et al., 2004; Gazelle \& Ladd, 2003). However, in contrast to East and Rook (1992) who found that isolated children rated their favourite sibling as most supportive and affectionate and their school friendships as least supportive, shy children did not have better or worse relationships with their siblings even though they were experiencing more peer problems (i.e. withdrawn behaviour at preschool) than less shy children. These results contrast the compensation model and suggest a carryover model may be at work since shyness was negatively related to peer competence but was not related to sibling relationship quality. As described earlier, the compensation model proposes that there will be an inverse relationship between sibling and peer relationships, such that children may compensate for poor relationships in one domain through a supportive relationship in the other domain. In contrast, the carryover model proposes similarity between sibling and peer relationships, suggesting that the skills learned in one domain will carryover to the other domain. This suggests that shy children may be forming healthier, less dependent sibling relationships than isolated children.

Siblings Relationships and Adjustment

Self-reported and parent-rated sibling relationship quality were moderately associated, however, analyses were conducted separately for both perspectives. Similarly, Ross and colleagues (2000) found a moderate correlation between self-reported and maternal-reported sibling relationship quality, but also reported differences in the patterns of associations between these differentially assessed variables and outcome variables. 
Since parents and children agree with one another but also express unique perspectives on the sibling relationship, it was of interest to assess the associations with outcome variables separately.

Overall, children with more positive sibling relationships report lower levels of internalizing problems, particularly loneliness. Children who had warmer and more supportive relationships with their sibling (both self- and parent-reported) reported less loneliness at preschool than children who had more distant and conflictual relationships with their sibling. These results support Dunn and colleagues (1994) longitudinal study suggesting a negative link between sibling relationship quality and internalizing problems as early as the preschool years. In contrast to hypotheses, the carryover model was not fully supported since sibling relationship quality was unrelated to indices of peer relationships at preschool or daycare. This may suggest that sibling relationship quality may be more closely related to emotional, rather than social adjustment when considering children as a whole. Because the sibling relationship is a familiar and safe environment as well as being intense and emotionally powerful (Dunn, 1983), children may find it easy to elicit emotional support from these relationships. However, the associations between sibling relationships and peer relationships may be more complex, suggesting other variables may be at play, such as child temperament (McCoy et al., 1994) and parentchild relationships (Richmond et al., 2005).

Family Structure Variables

Family structure variables (particularly birth order) were largely unrelated to shyness, sibling relationship quality or socio-emotional outcome variables. However, in line with previous research, sex composition of the sibling dyad was related to prosocial 
behaviour, such that girls with a female sibling were rated by teachers as more prosocial than boys with a male sibling (Furman \& Buhrmester, 1985; Minnett et al., 1983). We might expect this given the extensive literature suggesting that girls are more prosocial than boys (e.g. Eisenberg \& Miller, 1987). However, this may depend on how prosocial behaviors are defined. Feminine prosocial behaviour may be more compassionate and sympathetic, whereas masculine prosocial behaviours may include more agentic, engaged, and active behaviours, and thus be less overt to outside raters (Hastings, Parker \& Ladha, 2007). In relation to siblings, Minnett and colleagues (1983) found that sisters were more likely to praise and teach their sibling whereas brothers were more likely to engage in neutral or work/play interactions. This suggests that teachers may be more likely to detect the more obvious prosocial behaviours of girls. Moreover, the nature of girl's interactions with their female sibling may reinforce these behaviours in the peer group.

It must also be acknowledged that given the small sample size, power may not have been sufficient to detect birth order and age spacing effects. In previous research, younger siblings have been found have better peer relationships than older siblings (Kitzmann et al., 2002). However, as argued by theory of mind theorists, it is also possible that just the experience of having a sibling may promote socio-emotional competence, regardless of whether they are older or younger, closely spaced or widely spaced, by providing a social environment rich in incentive and opportunity for social and cognitive growth (Perner et al., 1994). Contemporary research has also suggested that the quality of the sibling relationship may be more important in children's socio-emotional development than the more "static" family structure variables (Brody, 1998). 
Shyness, Sibling Relationships, and Outcomes

The primary goal of this thesis research was to examine the moderating or protective role of sibling relationship quality in the association between shyness and socio-emotional functioning. Results indicated that sibling relationship quality did play a protective role in two indices of shy children's social and emotional adjustment.

To begin with, parental ratings of sibling relationship quality moderated the relation between shyness and anxious-fearful behaviours at preschool. As well, selfreported sibling relationship quality moderated the relation between shyness and loneliness. In both cases, the relations between shyness and negative outcomes increased among children with less positive sibling relationships and decreased among children with more positive sibling relationships. Thus, shy children who form a closer and more supportive relationship with their sibling may be protected from some of the negative outcomes typically experienced by shy children in early childhood.

It is of interest to note some differences in findings between self-reported and parent-reported sibling relationship quality. One explanation of these differences may be related to shared method variance (e.g., Ross et al., 2005). Accordingly, child-reported sibling relationship quality and loneliness were both self-report measures. This pattern of relations may also be present because loneliness describes an internal state, and may only be detected by the person experiencing it, whereas there may be external signs of anxious-fearful behaviour, such as "hovering" behaviour (Coplan et al., 2004). This may be why loneliness effects were not found when using parent-reported sibling relationship quality as the moderator but were found when using self-reported sibling relationship quality as the moderator. 
Nevertheless, these findings provide some of the first evidence to suggest that more positive sibling relationships may be particularly beneficial to shy children. These results also support previous research with socially-isolated children. For example, East and Rook (1992) reported that more positive sibling relationship quality partially protected these "at risk" children from poor emotional outcomes. However, in this case, the carryover model was supported as shy children who experienced more positive sibling relationships experienced better emotional as well as social adjustment (Hetherington, 1988; Stormshak et al., 1996). These results suggest that isolated children may be forming more dependent and exclusive relationships with their siblings to the detriment of their peer relationships. In contrast shy children may be forming healthy relationships with their siblings in which the skills and support derived from these relationships are carried over to their peer relationships. This may be due to the fact that socially isolated children may be actively rejected from the peer group, whereas the social difficulties shy children face are a result of internal forces, such as anxiety and poor emotion regulation (Rubin \& Asendorpf, 1993). These findings suggest that when shy children perceive emotional support, they may be more capable of regulating their anxiety and controlling their emotions in social situations; allowing them to interact with their peers in more constructive ways and their peers to be more accepting of them.

Conceptual similarities may also be drawn between sibling relationships and other relationships that involve significant others, such as a close parent-child relationship and friendship. In this regard, Coplan and colleagues (2008) have recently reported a buffering effect for shy children in terms of warm and supportive parenting. Several studies have also found evidence of similar buffering effects for friendship quality in 
terms of self-worth, social competence and internalizing problems for all children (e.g., Arbeau, 2008; Rubin, Dwyer, Booth-LaForce, Kim, Burgess, \& Rose-Krasnor, 2004). Fordham and Stevenson-Hinde (1999) have also found that involvement in a good quality friendship buffered shy children from internalizing problems by providing experiences that validate self-worth. It has also been suggested that positive teacher-child relationships can be a protective factor for shy children (Arbeau, Coplan, \& Weeks, in press). In relation to attachment theory, Mendelson and colleagues (1994) suggest that sibling relationships may involve their own internal models, whereby children develop confidence and trust as well as social skills from their siblings, which in turn influence their relationships with other children. Consequently, shy children who form close and supportive sibling relationships may feel more confident and secure at preschool and therefore interact with their environment in more appropriate and adaptive ways. Positive attachment and relationships with parents, friends, teachers, and siblings that provide emotional support may be particularly beneficial to shy children who may be vulnerable to poor peer relationships (Gazelle \& Ladd, 2003) and poor friendship quality (Wojslawowicz et al., 2002). When shy children have a network of social support to rely on they may be more likely to explore their social environment in healthy ways.

In contrast to hypotheses, birth order did not moderate the relationship between shyness and socio-emotional outcomes. It appears that shy children benefit from a high quality sibling relationship regardless of whether their sibling is younger or older. Again, these finding support the notion that relationship quality may matter more than the structure of the relationship (i.e., birth order) in terms of socio-emotional adjustment (Brody, 1998). In addition, the rich environment of the sibling relationship (mixed-age), 
regardless of birth order, may provide shy children with an environment to practice sociocognitive skills, cooperation and develop prosocial behaviours (Furman et al., 1979)

\section{Limitations and Future Directions}

The present study provided some of the first evidence to suggest that siblings, particularly the quality of the relationship, may serve a protective role for shy children in the preschool and daycare setting. Nevertheless there are some limitations that must be acknowledged. To begin with, the correlational nature of this thesis research does not allow conclusions of a causal nature to be drawn. Although these results could be interpreted in terms of the "protective" role of sibling relationships for shy children, other explanations cannot be discounted. For example, it may be that shy children who are less anxious at school also go on to form more positive relationships with their siblings. Moreover, other factors (e.g., parenting) may cause children who are shy to be both lonely at school and to form less positive relationships with their siblings. Given that this is a new area of study, longitudinal studies are needed to further clarify the relations between sibling relationship quality and adjustment for shy children. It would be of interest to investigate these associations as shy children mature into middle childhood and early adolescence.

In addition, the small sample size may not have given the study sufficient power to detect some associations. For example no shyness $\mathrm{x}$ birth order effects were found for any of the outcome variables, however many of the associations were close to significance particularly in terms of anxious-fearful behaviour and prosocial behaviour. Future research with larger sample sizes should look at whether shy children may benefit more from having a younger or older sibling in terms of socio-emotional outcomes as 
well as detecting further outcome effects in the association between shyness and sibling relationship quality. Since not enough children without siblings were obtained in this study to perform analysis, future research should look at only children compared to children with siblings, as well as the effects of having multiple siblings compared to one sibling, in terms of the benefits for shy children as well as socio-emotional adjustment outcomes for all children.

Although this study used multi-informants (self-report, parent-report and teacher report), children reported on their own sibling relationships as well as some of the outcome variables such as loneliness, perceived competence and perceived acceptance. This represents the issue of shared method variance, whereby, children may have used a self-serving bias in their assessments of their sibling relationships as well as outcome measures which may have inflated the relationships between these variables. However, a parental measure of sibling relationship quality was used as well as the self-reported measure. Since these measures were correlated and similar patterns of associations were found between the two measures, shared method variance should not have affected the results significantly.

In future research, observations of sibling relations may also be helpful in looking at aspects of the sibling relationship not detected with the use of questionnaires, such as co-operation and rates of interaction between siblings. Observations would also eliminate the problem of self-serving biases when using self-report data. Observations of peer interactions at preschool may also be helpful and would diminish any teacher biases that may be present. Exploring other socio-emotional outcome variables, such as anxiety, selfesteem and friendship quality may also be of interest. 
In addition, other aspects of the sibling relationship such as the amount of conflict compared to warmth, as well as factors that might influence the sibling relationship, such as attachment, marital relationships and parent-child relationships would be interesting to explore in relation to shyness and adjustment. It was interesting to note that shyness was related to parental marital status, such that parents rated children as more shy when they were separated or divorced than when in married or common-law relationships. Shy children may be directly affected by the instability and negativity of their parents' relationship causing them to internalize their negative emotions and further withdraw from their peers. This finding suggests that the quality of the parental relationship may also be a protective factor for shy children against negative socio-emotional outcomes. However, given that only eight parents were separated or divorced, future studies are needed to further clarify the relations between shyness and marital relationships.

Finally, because of the age of the participants, some children may not have understood the questions accurately during the individual interview, particularly the loneliness scale which has previously only been used with children at least 5 years of age. Indeed, child age was negatively related to loneliness, however the alpha for this scale was adequate $(\alpha=.73)$, suggesting that children as young as 4 years of age are able to accurately rate their feelings of loneliness.

The findings of this thesis research highlight the need for early intervention programs and therapy strategies aimed at developing warm and supportive sibling relationships for shy children. For example, Kennedy and Kramer (2008) tested an intervention strategy where 4-8 year old siblings were taught emotion regulation and social competency skills in order to improve their sibling relationships. Emotion 
regulation has previously been linked to the reduction of sibling conflict (Bedford \& Volling, 2004) and increased prosocial sibling interaction (Kramer, 2004). Emotion regulation has also been linked to the acquisition of social competencies in peer relationships such as co-ordinating play, conversation, perspective-taking, and conflict management. Children participating in the program needed less parental direction to control negative emotions and refrain from directing negative actions toward others following the program. In addition, higher levels of emotion regulation were linked with more positive sibling relationship quality at posttest. These results emphasize the value of strengthening children's emotion regulation processes as a mechanism for promoting high quality sibling and as well as peer relationships. Since shy children typically experience emotion regulation difficulties (e.g., Eisenberg \& Fabes, 1998) this type of intervention might be particularly beneficial for these children.

It may also be insightful to determine the mechanisms by which healthy versus dependent sibling relationships may form. Provided these mechanisms are determined, interventions that help children develop sibling relationships that provide social and emotional support but also allow them to explore relationships outside of the family can be developed. These healthy sibling relationships will be most important for children's later social development.

\section{Conclusions}

The results of this thesis research provide some of the first evidence to suggest that siblings, particularly the quality of the relationship, may serve a protective role in shy children's socio-emotional adjustment at preschool and daycare. In particular shy children who formed close and supportive sibling relationships were protected against 
some of the negative adjustment outcomes typically experienced by shy young children, such as loneliness and peer problems at preschool or daycare. In addition, a positive sibling relationship appeared to be beneficial for all children in terms of loneliness at preschool and daycare. Future research should further examine the role of sibling relationship quality in shy children's adjustment using longitudinal designs and incorporating observational methods into the design. Other variables that might influence the sibling relationship and shyness, such as marital relationships, parent-child relationships and friendship are also of interest. This research will be helpful for clinicians as well as developing early intervention programs targeted at developing healthy and positive sibling relationships. 


\section{References}

Abramovitch, R., Corter, C. M., \& Lando, B. (1979). Sibling interaction in the home. Child Development, 50(4), 997-1003.

Adler, A. (1958). The education of the individual. Oxford, England: Philosophical Library.

Aiken, L. S., \& West, S. G. (1991). Multiple regression: Testing and interpreting interactions. Thousand Oaks, CA, US: Sage Publications, Inc.

Ainsworth, M. D. (1972). Attachment and dependency: A comparison. Attachment and dependency. (). Oxford, England: V. H. Winston \& Sons.

Ainsworth, M. S., Blehar, M. C., Waters, E., \& Wall, S. (1978). Patterns of attachment: A psychological study of the strange situation. Oxford, England: Lawrence Erlbaum.

Arbeau, K. A. (2008). "Are you the right friend for me?" the effects of friendships on shy children's adjustment in middle childhood. Ottawa, Canada: Carleton University.

Arbeau, K. A., \& Coplan, R. J. (2009). “Are friendships always positive?” The effects of good quality friendships and social surrogate use on shy children's adjustment. In K.

A. Arbeau \& J. C. Bowker (co-chairs), The Friendships and Peer Relations of Shy/Withdrawn Children. Paper symposium presented at the Society for Research in Child Development Biennial Meeting, Denver, Colorado.

Arbeau, K. A., Coplan, R. J., \& Weeks, M. (in press). Shyness, teacher-child relationships, and socio-emotional adjustment in grade 1. International Journal of Behavioural Development.

Abramovitch, R., Corter, C. M., \& Lando, B. (1979). Sibling interaction in the home. Child Development, 50(4), 997-1003. Asendorpf, J. (1986). Shyness in middle and 
late childhood. In W. H. Jones, J, M. Cheek, \& S. R. Briggs (Eds.), Shyness:

Perspectives on research and treatment (pp. 91-103). New York: Plenum.

Asendorpf, J. B. (1990). Beyond social withdrawal: Shyness, unsociability, and peer avoidance. Human Development, 33, 250-259.

Asendorpf, J. B. (1991). Development of inhibited children's coping with unfamiliarity. Child Development. 33, 250-259.

Asendorpf, J. B., \& Meier, G. H. (1993). Personality effects on children's speech in everyday life: Sociability-mediated exposure and shyness-mediated reactivity to social situations. Journal of Personality and Social Psychology, 65, 1072-1083.

Asher, S. R., Hymel, S., \& Renshaw, P. D. (1984). Loneliness in children. Child Development, 55, 1456-1464.

Azmitia, M., \& Hesser, J. (1993). Why siblings are important agents of cognitive development: A comparison of siblings and peers. Child Development, 64(2), 430444.

Bandura, A. (1977). Self-efficacy: Toward a unifying theory of behavioral change. Psychological Review, 84(2), 191-215.

Bandura, A. (1986). Social foundations of thought and action: A social cognitive theory. Englewood Cliffs, NJ: Prentice Hall.

Bahr, S. J., Hoffmann, J. P., \& Yang, X. (2005). Parental and peer influences on the risk of adolescent drug use. Journal of Primary Prevention, 26(6), 529-551.

Baumrind, D. (1991). The influences of parenting style on adolescent competence and substance use. Journal of Early Adolescence, 11, 56-95. 
Baydar, N., Greek, A., \& Brooks-Gun, J. (1997). A longitudinal study of the effects of the birth of a sibling during the first 6 years of life. Journal of Marriage \& the Family, 59(4), 939-956.

Beardsall, L., \& Dunn, J. (1992). Adversities in childhood: Siblings' experiences, and their relations to self-esteem. Journal of Child Psychology and Psychiatry, 33(2), 349-359.

Bedford. V. H., \& Volling, B. (2004). A dynamic ecological systems perspective on emotion regulation development within the sibling relationship context. In F. R. Lang \& K. Fingerman (Eds.), Growing together: Personal relationships across the life span (pp. 76-102). New York: Cambridge University Press.

Bell, N. J., Schoenrock, C. J., Young, M., Avery, W., Croft, C. A., \& Lane, S. (1986). Family constellation, social competence, and sex-role development. Journal of Genetic Psychology, 146, 273-275.

Bishop, G., Spence, S. H., \& McDonald, C. (2003). Can parents and teachers provide a reliable and valid report of behavioral inhibition? Child Development, 74. 1899-1917.

Boer, F., \& Dunn, J. (1992). Children's sibling relationships: Developmental and clinical issues. Hillsdale, NJ, England: Lawrence Erlbaum Associates, Inc.

Boer, F., Westenberg, P. M., McHale, S. M., Updegraff, K. A., \& Stocker, C. M. (1997). The factorial structure of the sibling relationship inventory (SRI) in Aamerican and Dutch samples. Journal of Social and Personal Relationships, 14(6), 851-859.

Bögels, S. M., van Oosten, A., Muris, P., \& Smulders, D. (2001). Familial correlates of social anxiety in children and adolescents. Behaviour Research and Therapy, 39(3), 273-287. 
Bohlin, G., Hagekull, B., \& Anderson, K. (2005). Behavioral inhibition as a precursor of peer social competence in early school age: The interplay with attachment and nonparental care. Merrill-Palmer Quarterly, 51, 1-19.

Boivin, M., \& Hymel, S. (1997). Peer experiences and social self-perceptions: a sequential model. Developmental Psychology, 33, 135-145.

Booth, C. L., Rose-Krasnor, L., McKinnon, J., \& Rubin, K. H. (1994). Predicting social adjustment in middle childhood: The role of preschool attachment security and maternal style. Social Development, 3, 189-204.

Booth-LaForce, C., \& Oxford, M. L. (2008). Trajectories of social withdrawal from grades 1 to 6: Prediction from early parenting, attachment, and temperament. Developmental Psychology, 44(5), 1298-1313.

Bowlby, J. (1969). Disruption of affectional bonds and its effects on behavior. Canada's Mental Health Supplement, 59, 12.

Bowlby, J. (1973). Attachment and loss: Attachment. New York: Basic Books.

Bradshaw, S. D. (1998). I'll go if you will: Do shy persons utilize social surrogates? Journal of Social and Personal Relationships, 15(5), 651-669.

Bretherton, I. (1985). Attachment theory: Retrospect and prospect. Monographs of the Society for Research in Child Development, 50(1-2), 3-35.

Brody, G. H. (1998). Sibling relationship quality: Its causes and consequences. Annual Review of Psychology, 49, 1-24.

Brody, G. H., Stoneman, Z., \& Burke, M. (1987). Child temperaments, maternal differential behavior, and sibling relationships. Developmental Psychology, 23(3), $354-362$. 
Brody, G. H., Stoneman, Z., \& McCoy, J. K. (1994). Forecasting sibling relationships in early adolescence from child temperaments and family processes in middle childhood. Child Development, 65(3), 771-784.

Brody, G. H., Stoneman, Z., \& MacKinnon, C. E. (1982). Role asymmetries in interactions among school-aged children, their younger siblings, and their friends. Child Development, 53(5), 1364-1370.

Brody, G. H., Stoneman, Z., MacKinnon, C. E., \& MacKinnon, R. (1985). Role relationships and behavior between preschool-aged and school-aged sibling pairs. Developmental Psychology, 21(1), 124-129.

Brown, J. R., \& Dunn, J. (1992). Talk with your mother or your sibling? developmental changes in early family conversations about feelings. Child Development, 63(2), 336349.

Brucsh, M. A., Hammer, R. J., \& Heimberg, R. G. Gorsky, J. M., Collins, T. M., \& Berger, P. A. (1995)89). Shyness and sociability re-examined: A multicomponent analysis. Journal of Personality and Social Psychology, 57, 904-915. Shyness and public self-consciousness: Additive or interactive relation with social interaction? Journal of Personality, 63, 47-63.

Buhs, E. S., Ladd, G. W., \& Herald, S. L. (2006). Peer exclusion and victimization: Processes that mediate the relation between peer group rejection and children's classroom engagement and achievement? Journal of Educational Psychology, 98(1), 1-13. 
Bukowski, W. M. (1990). Age differences in children's memory of information about aggressive, socially withdrawn, and prosociable boys and girls. Child Development, $61(5), 1326-1334$.

Burgess, K. B., Rubin, K. H., Cheah, C. S. L., \& Nelson, L. J. (2001). Behavioural inhibition, social withdrawal and parenting. In W. R. Crozier \& L. E. Alden (Eds.), International handbook of social anxiety: Concepts, research and interventions relating to the self and shyness (pp. 173-158). New York: John Wiley \& Sons.

Buss, A., \& Plomin, R. (1984). Temperament: Early developing personality traits. Hillsdale, NJ: Erlbaum.

Byrne, B. M. (1996). Measures of self-concept for young children. Washington, DC: American Psychological Association.

Calkins, S. D, \& Fox, N. A. (1992). The relations among infant temperament, security of attachment, and behavioral inhibition at twenty-four months. Child Development, 63, 1456-1472.

Carey, S. (1985). Conceptual change in childhood. Cambridge, MA: MIT Press

Cassidy, J., \& Asher, S. R. (1992). Loneliness and peer relations in young children. Child Development, 63(2), 350-365.

Cheek, J. M., \& Busch, C. M. (1981). The influence of shyness on loneliness in a new situation. Personality and Social Psychology Bulletin, 7, 572-577.

Cicirelli, V. G. (1972). The effect of sibling relationship on concept learning of young children taught by child-teachers. Child Development, 43(1), 282-287.

Coldwell, J., Pike, A., \& Dunn, J. (2008). Maternal differential treatment and child adjustment: A multi-informant approach. Social Development, 17(3), 596-612. 
Cole, A., \& Kerns, K. A. (2001). Perceptions of sibling qualities and activities of early adolescents. Journal of Early Adolescence, 21(2), 204-226.

Coplan, R. J., Arbeau, K. A., \& Armer M. (2008). Don't fret, be supportive! Maternal characteristics linking child shyness to psychosocial and school adjustment in kindergarten. Journal of Abnormal Child Psychology, 36(3), 359-371.

Coplan, R. J., Armer, M. (2005). 'Talking yourself out of being shy': Shyness, expressive vocabulary, and adjustment in preschool. Merrill-Palmer Quarterly, 51, 20-41.

Coplan, R. J., Closson, L. M., \& Arbeau, K. A. (2007a.). Gender differences in the behavioral associates of loneliness and social dissatisfaction in kindergarten. Journal of Child Psychology and Psychiatry, 48(10), 988-995.

Coplan, R. J., Findlay, L. C., \& Nelson, L. J. (2004) Characteristics of preschoolers with lower perceived competence. Journal of Abnormal Child Psychology, 32(4), 399408.

Coplan, R. J., Girardi, A., Findlay, L. C., \& Frohlick, S. L. (2007b). Understanding solitude: Young children's attitudes and responses toward hypothetical socially withdrawn peers. Social Development, 16(3), 390-409.

Coplan, R. J., Prakash K., O’Neil K., \& Armer, M. (2004). Do you 'want' to play? Distinguishing between conflicted-shyness and social disinterest in early childhood. Developmental Psychology, 40(2), 244-258.

Coplan, R. J., Rubin, K. H., Fox, N. A., Calkins, S. D., \& Stewart, S. L. (1994). Being alone, playing alone, and acting alone: Distinguishing among reticence, and passive and active-solitude in young children. Child Development, 65(1), 129-138. 
Crozier, W. R. (1995). Shyness and self-esteem in middle childhood. British Journal of Educational Psychology, 65, 85-95.

Crozier, W. R., \& Birdsey, N. (2003). Shyness, sensation seeking and birth-order position. Personality and Individual Differences, 35(1), 127-134.

Crozier, W. R, Perkins P. (2002). Shyness as a factor when assessing children. Educational Psychological in Practice, 18(3), 239-244.

Cummings, E. M., Zahn-Waxler, C., \& Radke-Yarrow, M. (1981). Young children's responses to expressions of anger and affection by others in the family. Child Development, 52(4), 1274-1282.

Cutting, A. L., \& Dunn, J. (2006). Conversations with siblings and with friends: Links between relationship quality and social understanding. British Journal of Developmental Psychology, 24(1), 73-87.

Daniels, D., \& Plomin, R. (1985). Origins of individual differences in infant shyness. Developmental Psychology, 21, 118-121.

Davidson, R. J., \& Fox, N. A. (1989). Frontal brain asymmetry predicts infants' response to maternal separation. Journal of Abnormal Psychology, 98(2), 127-131.

Degnan, K. A., Henderson, H. A, Fox, N. A., \& Rubin, K. H. (2008) Predicting social wariness in middle childhood: The moderating roles of child care history, maternal personality, and maternal behavior. Social Development, 17(3), 471-487.

Dekovic, M., \& Janssens, J. M. A. M. (1992). Parents' child-rearing styles and child's sociometric status. Developmental Psychology, 28, 925-932.

Dunn, J. (1983). Sibling relationships in early childhood. Child Development, 54(4), 787811. 
Dunn, J. (1984). Sisters and brothers. London: Fontana

Cutting, A. L., \& Dunn, J. (2006). Conversations with siblings and with friends: Links between relationship quality and social understanding. British Journal of Developmental Psychology, 24(1), 73-87.

Dunn, J. (1995). Children as psychologists: The later correlates of individual differences in understanding of emotions and other minds. Cognition \& Emotion, 9(2-3), 187 201.

Dunn, J. (2001). The development of children's conflict and prosocial behaviour: Lessons from research on social understanding and gender. In J. Hill, \& B. Maughan (Eds.), Conduct disorders in childhood and adolescence. (pp. 49-66). New York, NY, US: Cambridge University Press.

Dunn, J., Bretherton, I., \& Munn, P. (1987). Conversations about feeling states between mothers and their young children. Developmental Psychology, 23, 1-8.

Dunn, J., \& Dale, N. (1984). I a daddy: 2-year-olds' collaboration in joint pretend play with sibling and mother. In I. Bretherton (Ed.), Symbolic play (pp. 131-158). New York: Academic Press.

Dunn, J. (2002). Sibling relationships. In P. K. Smith, \& C. H. Hart (Eds.), Blackwell handbook of childhood social development. (pp. 223-237). Malden, MA, US: Blackwell Publishing.

Dunn, J., \& McGuire, S. (1992). Sibling and peer relationships in childhood. Journal of Child Psychology and Psychiatry, 33(1), 67-105.

Dunn, J., \& Munn, P. (1986). Siblings and the development of prosocial behaviour. International Journal of Behavioral Development, 9(3), 265-284. 
Dunn, J., Slomkowski, C., \& Beardsall, L. (1994). Sibling relationships from the preschool period through middle childhood and early adolescence. Developmental Psychology, 30(3), 315-324.

Dunn, J., Slomkowski, C., Beardsall, L., \& Rende, R. (1994). Adjustment in middle childhood and early adolescence: Links with earlier and contemporary sibling relationships. Journal of Child Psychology and Psychiatry, 35(3), 491-504.

East, P. L., \& Rook, K. S. (1992). Compensatory patterns of support among children's peer relationships: A test using school friends, nonschool friends, and siblings. Developmental Psychology, 28(1), 163-172.

Eisenberg, N., \& Fabes, R. A. (1998). Prosocial development. In W. Damon (series Ed.) \& N. Eisenberg (vol. Ed.), Handbook of child psychology (5th ed.): Vol. 3. Social, emotional and personality development (pp. 701-778).

Erickson, M. F., Sroufe, L. A., Egeland, B. (1985). The relationship between quality of attachment and behavior problems in preschool in a high-risk sample. Monographs of the Society for Research in Child Development, 50(1-2), 147-166.

Evans, M. A. (2001). Shyness in the classroom and home. In W. R. Crozier, \& L. E. Alden (Eds.), International handbook of social anxiety: Concepts, research and interventions relating to the self and shyness (pp. 159-183). Westport, CT: John Wiley \& Sons Ltd.

Findlay, L. C., Girardi, A., \& Coplan, R. J. (2006). Links between empathy, social behavior, and social understanding in early childhood. Early Childhood Research Quarterly, 21(3), 347-359. 
Fordham, K., \& Stevenson-Hinde, J. (1999). Shyness, friendship quality, and adjustment during middle childhood. Journal of Child Psychology and Psychiatry, 40(5), 757768.

Fox, N. A., Bell, M. A., \& Jones, N. A. (1992). Individual differences in response to stress and cerebral asymmetry. Developmental Neuropsychology, 8(2-3), 161-184.

Fox, N. A., Henderson, H. A., Marshall, P. J., Nichols, K. E., \& Ghera, M. M. (2005). Behavioral inhibition: linking biology and behavior within a developmental framework. Annual Review of Psychology, 56, 235-262.

Fox, N. A., Henderson, H. A., Rubin. K. H., Calkins, S. D., \& Schmidt, L. A. (2001). Continuity and discontinuity of behavioral inhibition and exuberance: Psychophysiological and behavioral influences across the first 4 years of life. Child Development, $72,1-21$.

Furman, W., \& Buhrmester, D. (1985). Children's perceptions of personal relationships in their social networks. Developmental Psychology, 21, 1016-1024.

Furman, W., Rahe, D.F., \& Hartup, W.W. (1979). Rehabilitation of socially withdrawn preschool children through mixed-age and same-age socialization. Child Development, 50, 915-922.

Gass, K., Jenkins, J., \& Dunn, J. (2007). Are sibling relationships protective? A longitudinal study. Journal of Child Psychology and Psychiatry, 48(2), 167-175.

Garcia Coll, C., Kagan, J., \& Reznick, J. S. (1984). Behavioral inhibition in young children. Child Development, 55(3), 1005-1019.

Gass, K., Jenkins, J., \& Dunn, J. (2007). Are sibling relationships protective? A longitudinal study. Journal of Child Psychology and Psychiatry, 48(2), 167-175. 
Gazelle, H., \& Ladd, G. W. (2003). Anxious solitude and peer exclusion: A diathesisstress model of internalizing trajectories in childhood. Child Development, 74, 257278.

Gazelle, H., \& Rudolph, K. D. (2004). Moving toward and away from the world: Social approach and avoidance trajectories in anxious solitary youth. Child Development, $75,829-849$.

Gopnik, A. (1988). Conceptual and semantic development as theory change. Mind and Language, 3, 197-217.

Goswick, R. A., \& Jones, W. H. (1981). Loneliness, self-concept, and adjustment. Journal of Psychology: Interdisciplinary and Applied, 107(2), 237-240.

Harrist, A. W., \& Bradley, K. D. (2003). "You can't say you can't play": Intervening in the process of social exclusion in the kindergarten classroom. Early Childhood Research Quarterly, 18(2), 185-205.

Harrist, A. W., Zaia, A. F., Bates, J. E., Dodge, K. A., \& Pettit, G. S. (1997). Subtypes of social withdrawal in early childhood: Sociometric status and social-cognitive differences across four years. Child Development, 68(2), 278-294.

Hart, C. H., Yang, C., Nelson, L. J., Robinson, C. C., Olsen, J. A., Nelson, D. A., Porter, C. L., Jin, S., Olsen, S. F., \& Wu, P. (2000). Peer acceptance in early childhood and subtypes of socially withdrawn behaviour in China, Russia and the United States. International Journal of Behavioral Development, 241, 73-81.

Harter, S., \& Pike, R. (1984). The pictorial scale of perceived competence and social acceptance for young children. Child Development, 55(6), 1969-1982. 
Hastings, P. D., \& Rubin, K. H. (1999). Predicting mothers' beliefs about preschool-aged children's social behavior: Evidence for maternal attitudes moderating child effects. Child Development, 70(3), 722-741.

Hastings, P. D., Zahn-Waxler, C., \& McShane, K. (2006). We are, by nature, moral creatures: Biological bases of concern for others. In M. Killen, \& J. G. Smetana (Eds.), Handbook of moral development. (pp. 483-516). Mahwah, NJ: Lawrence Erlbaum Associates Publishers.

Hayward, C., Killen, J. D., Kraemer, H. C., \& Taylor, C. B. (1998). Linking self-reported childhood behavioral inhibition to adolescent social phobia. Journal of the American Academy of Child and Adolescent Psychiatry, 37, 1308-1316.

Henderson, H. A, Marshall, P. J., Fox, N. A, \& Rubin, K. H. (2004). Psychophysiological and behavioral evidence for varying forms and functions of nonsocial behaviors in preschoolers. Child Development, 75(1), 251-263.

Herrera, C., \& Dunn, J. (1997). Early experiences with family conflict: Implications for arguments with a close friend. Developmental Psychology, 33(5), 869-881.

Hetherington, E. M. (1988). Parents, children, and siblings: Six years after divorce. In R. A. Hinde \& Stevenson-Hinde (Eds.), Relationships within families: Mutual influences (pp. 311-331). Oxford: Clarendon Press.

Howe, N. (1991). Sibling-directed internal state language, perspective taking, and affective behavior. Child Development, 62(6), 1503-1512.

Howe, N., \& Ross, H. S. (1990). Socialization, perspective-taking, and the sibling relationship. Developmental Psychology, 26, 160-165. 
Hudson, J. L., \& Rapee, R. M. (2001). Parent-child interactions and anxiety disorders: An observational study. Behavior Research Therapy. 39, : 1411-1427.

Hymel, S., Bowker, A., \& Woody, E. (1993). Aggressive versus withdrawn unpopular children: variations in peer and self-perceptions in multiple domains. Child Development, 64, 879-896.

Hymel, S., Rubin, K. H., Rowden, L., \& LeMare, L. (1990). Children's peer relationships: Longitudinal prediction of internalizing and externalizing problems from middle to late childhood. Child Development, 61(6), 2004-2021.

Jenkins, J. M., \& Astington, J. W. (1996). Cognitive factors and family structure associated with theory of mind development in young children. Developmental Psychology, 32(1), 70-78

Jones, W. H., Rose, J., \& Russell, D. W. (1990). Loneliness and social anxiety. In H. Leitenberg (Ed.), Handbook of social and evaluation anxiety. (pp. 247-266). New York, NY, US: Plenum Press.

Kagan, J., Reznick, S., \& Snidman, N. (1987). The physiology and psychology of behavioural inhibition in children. Child Development, 58, 1459-1473.

Kagan, J., Snidman, N., \& Arcus, D. (1993). On the temperamental categories of inhibited and uninhibited children. In K. H. Rubin, \& J. B. Asendorpf (Eds.), Social withdrawal, inhibition, and shyness in childhood, pp. 19-28. Hillsdale, NJ: Lawrence Erlbaum Associates.

Kennedy, D. E., \& Kramer, L. (2008). Improving emotion regulation and sibling relationship quality: The more fun with sisters and brothers program. Family Relations, 57(5), 567-578. 
Kim, J., McHale, S. M., Crouter, A. C., \& Osgood, D. W. (2007). Longitudinal linkages between sibling relationships and adjustment from middle childhood through adolescence. Developmental Psychology, 43(4), 960-973.

Kitzmann, K. M., Cohen, R., \& Lockwood, R. L. (2002). Are only children missing out? Comparison of the peer-related social competence of only children and siblings. Journal of Social and Personal Relationships, 19(3), 299-316.

Kramer, L. (2004). Experimental interventions in sibling relations. In R. D. Conger, F. O. Lorenz, \& K. A. S. Wickrama (Eds.), Continuity and change in family relations: Theory, methods and empirical findings (pp. 345-380). Mahwah, NJ: Erlbaum.

Kramer, L. (2008). Moving beyond sibling rivalry, Manuscript submitted for publication.

Kramer, L., \& Gottman, J. M. (1992). Becoming a sibling: "with a little help from my friends." Developmental Psychology, 28(4), 685-699.

Ladd, G. W. (2006). Peer rejection, aggressive or withdrawn behavior, and psychological maladjustment from ages 5 to 12: An examination of four predictive models. Child Development, 77, 822-846.

Ladd, G. W., \& Burgess, K. B. (1999). Charting the relationship trajectories of aggressive, withdrawn, and aggressive/withdrawn children during early grade school. Child Development, 70, 910-929.

Ladd, G. W., \& Profilet, S. M. (1996). The child behavior scale: A teacher-report measure of young children's aggressive, withdrawn, and prosocial behaviors. Developmental Psychology, 32(6), 1008-1024. 
Ladd, G. W., \& Troop-Gordon, W. (2003). The role of chronic peer difficulties in the development of children's psychological adjustment problems. Child Development, 74(5), 1344-1367.

Lemerise, E., \& Arsenio, W. (2000). An integrated model of emotion processes and cognition in social information processing. Child Development, 71, 107-118.

Lockwood, R. L., Kitzmann, K. M., \& Cohen, R. (2001). The impact of sibling warmth and conflict on children's social competence with peers. Child Study Journal, 3l(1), 47-69.

MacDonald, K., \& Parke, R. D. (1984). Bridging the gap: Parent-child play interaction and peer interactive competence. Child Development, 55(4), 1265-1277.

Manassis, K., \& Bradley, S. J. (1994). The development of childhood anxiety disorders: Toward an integrated model. Journal of Applied Developmental Psychology, 15, 345366.

Marks, A., Ensor, R., \& Hughes, C. (2009). Young siblings' antisocial acts: Links with later adjustment. Poster presentation presented at the Society or Research in Child Development Biennial Meeting, Denver, Colorado.

McCoy, J. K., Brody, G. H., \& Stoneman, Z. (1994). A longitudinal analysis of sibling relationships as mediators of the link between family processes and youths' best friendships. Family Relations, 43(4), 400-408.

McFadyen-Ketchum, S. A., Bates, J. E., Dodge, K. A., \& Pettit, G. S. (1996). Patterns of change in early childhood aggressive-disruptive behavior: Gender differences in predictions from early coercive and affectionate mother-child interactions. Child Development. 67, 2417-2433. 
McGuire, S., McHale, S. M., \& Updegraff, K. (1996). Children's perceptions of the sibling relationship in middle childhood: Connections within and between family relationships. Personal Relationships, 3(3), 229-239.

McHale, S. M., \& Crouter, A. C. (1996). The family contexts of children's sibling relationships. In G. H. Brody (Ed.), Sibling relationships: Their causes and consequences. (pp. 173-195). Westport, CT, US: Ablex Publishing.

McHale, S. M., Crouter, A. C., McGuire, S. A., \& Updegraff, K. A. (1995). Congruence between mothers' and fathers' differential treatment of siblings: Links with family relations and children's well-being. Child Development, 66(1), 116-128.

McHale, S. M., Soli, A. R., Groenendyk, A. E., \& Shanahan, L. (2009). Differential treatment of siblings in middle childhood and adolescence. In K. Pillemer \& S. M. McHale (co-chairs), Within-Family Differences in Parent-Child Relations Over the Life Course. Paper symposium presented at the Society for Research in Child Development Biennial Meeting, Denver, Colorado.

McManis, M. H, Kagan, J., Snidman, N. C., \& Woodward, S. A. (2002). EEG asymmetry, power, and temperament in children. Developmental Psychobiology, 41, $169-177$.

Mendelson, M. J., Aboud, F. E., \& Lanthier, R. P. (1994). Kindergartners' relationships with siblings, peers, and friends. Merrill-Palmer Quarterly, 40(3), 416-435.

Miller, P. A., Eisenberg, N., Fabes, R. A., \& Shell, R. (1996). Relations of moral reasoning and vicarious emotion to young children's prosocial behavior toward peers and adults. Developmental Psychology, 32, 210-219. 
Miller, N., \& Maruyama, G. (1976). Ordinal position and peer popularity. Journal of Personality and Social Psychology, 33(2), 123-131.

Mills, R. S. L., \& Rubin, K. H. (1990). Parental beliefs about problematic social behaviors in early childhood. Child Development, 61, 138-151.

Minnett, A. M., Vandell, D. L., \& Santrock, J. W. (1983). The effects of sibling status on sibling interaction: Influence of birth order, age spacing, sex of child, and sex of sibling. Child Development, , 54(4), 1064-1072.

Minuchin, P. (1988). Relationships within the family: a systems perspective on development. In R. A. Hinde \& J. Stevenson-Hinde (Eds.) Relationships within Families: Mutual Influences (pp.7-26). Oxford: Clarendon Press.

Moore, D., \& Schultz, N. R. (1983). Loneliness at adolescence: Correlates, attributions, and coping. Journal of Youth and Adolescence, 12(2), 95-100.

Munn, P., \& Dunn, J. (1989). Temperament and the developing relationship between siblings. International Journal of Behavioral Development, 12(4), 433-451.

Nader, K., \& LeDoux, J. (1999). The neural circuits that underlie fear. In L. A. Schmidt \& J. Schulkin (Eds.), Extreme fear, shyness and social phobia: Origins, biological mechanisms, and clinical outcomes (pp. 119-139). New York: Oxford University Press.

Nelson, L. J., Rubin, K. H., \& Fox, N. A. (2005). Social and nonsocial behaviors and peer acceptance: A longitudinal model of the development of self-perceptions in children ages 4 to 7 years. Early Educational. Development, 20, 185-200.

Patterson, G. R. (1986). Performance models for antisocial boys. American Psychologist, $41(4), 432-444$. 
Patterson, G. R., Dishion, T. J., \& Bank, L. (1984). Family interaction: A process model of deviancy training. Aggressive Behavior, 10(3), 253-267.

Peplau, L. A., \& Perlman, D. (1982). Perspectives on loneliness. In L. A. Peplau and D. Perlman (Eds.), Loneliness: A sourcebook of current theory, research and therapy. New York: Wiley-Interscience.

Pérez-Granados, D. R., \& Callanan, M. A. (1997). Conversations with mothers and siblings: Young children's' semantic and conceptual development. Developmental Psychology, 33(1), 120-134.

Perner, J. (1991). Understanding the representational mind. Cambridge, MA, US: The MIT Press.

Perner, J., Ruffman, T, \& Leeham, S. R. (1994). Theory of mind is contagious. You catch it from your sibs. Child Development, 65, 1228-1238.

Phillipsen, L. C., Bridges, S. K., McLemore, T. G., \& Saponaro, L. A. (1999). Perceptions of social behavior and peer acceptance in kindergarten. Journal of Research in Childhood Education, 14(1), 68-77.

Piaget, J. (1965). The moral judgment of the child. New York: Free Press.

Plomin, R., \& Daniels, D. (1986). Genetics and shyness. In W. H. Jones, J. M. Cheek, \& S. R. Brigss (Eds.), Shyness: Perspectives on research and treatment (pp. 63-90). New York: Plenum.

Plomin, R., \& DeFries, J. C. (1983). The Colorado Adoption Project. Child Development, $54,276-289$.

Prakash, K., \& Coplan, R. J. (2003). Shy skaters? Shyness, coping, and adjustment outcomes in female adolescent figure skaters. Athletic Insight, 5, 1-19. 
Prior, M., Smart, D., Sanson, A., \& Oberklaid F. (2000). Does shy-inhibited temperament in childhood lead to anxiety problems in adolescence? Journal of the American Academy of Child and Adolescent Psychiatry, 39, 461-468.

Ram, A., \& Ross, H. S. (2001). Problem-solving, contention, and struggle: How siblings resolve a conflict of interests. Child Development, 72(6), 1710-1722.

Richman, N., Stevenson, J., \& Graham, P. J. (1982). Pre-school to school: A behavioural study. Behavioural Development, A Series of Monographs, 228.

Richmond, M. K., \& Stocker, C. M. (2008). Longitudinal associations between parents' hostility and siblings' externalizing behavior in the context of marital discord. Journal of Family Psychology, 22(2), 231-240.

Richmond, M. K., Stocker, C. M., \& Rienks, S. L. (2005). Longitudinal associations between sibling relationship quality, parental differential treatment, and children's adjustment. Journal of Family Psychology. Special Issue: Sibling Relationship Contributions to Individual and Family Well-being, 19(4), 550-559.

Robinson, J. L., Zahn-Waxler, C., \& Emde, R. N. (1994). Patterns of development in early empathic behavior: Environmental and child constitutional influences. Social Development, 3, 125-145.

Rose-Krasnor, L., Rubin, K. H., Booth, C. L., \& Coplan, R. (1996). The relation of maternal directiveness and child attachment security to social competence in preschoolers. International Journal of Behavioral Development, 19(2), 309-325.

Ross, H., Ross, M., Stein, N., \& Trabasso, T. (2006). How siblings resolve their conflicts: The importance of first offers, planning, and limited opposition. Child Development, $77(6), 1730-1745$. 
Ross, H., Stein, N., Trabasso, T., Woody, E., \& Ross, M. (2005). The quality of family relationships within and across generations: A social relations analysis. International Journal of Behavioral Development, 29(2), 110-119.

Ross, H., Woody, E., Smith, M., \& Lollis, S. (2000). Young children's appraisals of their sibling relationships. Merrill-Palmer Quarterly, 46(3), 441-464.

Rothbart, M. K., \& Bates, J. E. (1998). Temperament. In W. Damon \& N. Eisenberg (Eds.), Handbook of Child Psychology: Vol. 3, Social, Emotional and Personality Development $\left(5^{\text {th }}\right.$ ed., pp. 105-176). New York: John Wiley and Sons.

Renken, B., Egeland, B., Marvinney, D., Mangelsdorf, S., \& Sroufe, L. A, (1989). Early childhood antecedents of aggression and passive-withdrawal in early elementary school. Journal of Personality, 57(2), 257-281.

Rubin, K. H., \& Asendorpf, J. B. (1993). Social withdrawal, inhibition, and shyness in childhood: conceptual and definitional issues. In K. H. Rubin \& J. B. Asendorpf (Eds.), Social withdrawal, inhibition and shyness in childhood (pp. 291-314). Hillsdale, NJ: Lawrence Erlbaum Associates.

Rubin, K. H., Bowker, J., \& Gazelle, H. (in press). Social withdrawal in childhood and adolescence: Peer relationships and social competence. In K. H. Rubin, \& R. J. Coplan (Eds.), The Development of Shyness and Social Withdrawal in Childhood and Adolescence. New York: Guilford.

Rubin, K. H., Burgess, K. B., \& Coplan, R. J. (2002)a. Social withdrawal and shyness. In P. K. Smith, \& C. H. Hart (Eds.). Blackwell Handbook of Childhood Social Development (pp. 329-352). Great Britain: Blackwell Publishers. 
Rubin, K. H., Burgess, K. B., Hastings, P. D. (2002)b. Stability and social-behavioral consequences of toddlers' inhibited temperament and parenting. Child Development, $73,483-495$.

Rubin, K. H., Chen, X., \& Hymel, S. (1993). Socioemotional characteristics of withdrawn and aggressive children. Merrill-Palmer Quarterly, 39(4), 518-534.

Rubin, K. H., Chen, X., McDougall, P., Bowker, A., \& McKinnon, J. (1995). The Waterloo Longitudinal Project: Predicting adolescent internalizing and externalizing problems from early and mid-childhood. Developmental Psychopathology, 7,751764.

Rubin, K. H., \& Coplan, R. J. (2004). Paying attention to and not neglecting social withdrawal and social isolation. Merrill-Palmer Q. 50: 506-534.

Rubin, K. H., Coplan, R., Chen, X., Buskirk, A. A., \& Wojslawowicz, J. C. (2005). Peer relationships in childhood. In M. H. Bornstein, \& M. E. Lamb (Eds.), Developmental science: An advanced textbook (5th ed.) (pp. 469-512). Mahwah, NJ, US: Lawrence Erlbaum Associates Publishers.

Rubin, K. H., Coplan, R. J., \& Bowker, J. C., \& Menzer (in press). Social withdrawal and shyness. In P.K. Smith \& C. Hart (Eds.), Blackwell's Handbook of Childhood Social Development (2nd Edition). New York: Wiley-Blackwell.

Rubin, K. H., Dwyer, K. M., Booth-LaForce, C., Kim, A. H., Burgess, K. B., \& RoseKrasnor, L. (2004). Attachment, friendship, and psychosocial functioning in early adolescence. Journal of Early Adolescence, 24(4), 326-356.

Rubin, K. H., Hymel, S., \& Mills, R. S. L. (1989). Sociability and social withdrawal in childhood: Stability and outcomes. Journal of Personality, 57, 237-255. 
Rubin, K. H., \& Rose-Krasner, L. (1992). Interpersonal problem solving and social competence in children. In V. B. Van Hasselt \& M. Hersen (Eds.), Handbook of social development: A lifespan perspective (pp. 283-323). NY: Plenum Press.

Rubin, K. H, \& Krasnor, L. R. (1986). Social-cognitive and social behavioral perspectives on problem solving. In M. Perlmutter (Ed.), Cognitive perspectives on children's social and behavioral development. The Minnesota Symposia on Child Psychology Vol. 18 (pp. 1-68). Hillsdale, N.J.: Erlbaum.

Rubin, K. H, \& Mills, R. S. L. (1988). The many faces of social isolation in childhood. Journal of Consulting and Clinical Psychology, 56(6), 916-924.

Rubin, K. H., Nelson, L. J., Hastings, P. D., \& Asendorpf, J. B. (1999). The transaction between parents' perceptions of their children's shyness and their parenting styles. Int. Journal of Behavioral Development, 23, 937-958.

Rubin, K. H., Wojslawowicz, J. C., Rose-Krasnor, L., Booth-LaForce, C., \& Burgess, K. B. (2006). The best friendships of Shy/Withdrawn children: Prevalence, stability, and relationship quality. Journal of Abnormal Child Psychology, 34(2), 143-157.

Sampson, E. E., \& Hancock, F. T. (1967). An examination of the relationship between ordinal position, personality, and conformity: An extension, replication, and partial verification. Journal of Personality and Social Psychology, 5(4), 398-407.

Shamir-Essakow, G., Ungerer, J. A., \& Rapee, R. M. (2005). Attachment, behavioral inhibition, and anxiety in preschool children. Journal of Abnormal Child Psychology, $33,131-143$.

Shanahan, L., McHale, S. M., Crouter, A. C., \& Osgood, D. W. (2008). Linkages between parents' differential treatment, youth depressive symptoms, and sibling 
relationships. Journal of Marriage and Family, 70(2), 480-494. Schmidt, L. A. (1999). Frontal brain electrical activity in shyness and sociability. Psychological Science, $10,316-320$.

Schmidt, L. A., \& Fox, N. A. (1999). Conceptual, biological, and behavioral distinctions among different categories of shy children. In L. A. Schmidt \& J. Schulkin (Eds.), Extreme fear, shyness and social phobia: Origins, biological mechanisms, and clinical outcomes (pp. 47-66). New York: Oxford University Press.

Schneider, B. H. (1999). A multi-method exploration of the friendships of children considered socially withdrawn by their peers. Journal of Abnormal Psychology, 27, $115-123$.

Shulman, S., Elicker, J., Sroufe, L. A. (1994). Stages of friendship growth in preadolescence as related to attachment history. Journal of Social and Personal Relationships, 11(3), 341-361.Schwartz, C. E, Snidman, N., Kagan, J. (1999). Adolescent social anxiety as an outcome of inhibited temperament in childhood. Journal of the American Academy of Child and Adolescent Psychiatry, 38, 10081015.

Schneider, B. H. (1999). A multi-method exploration of the friendships of children considered socially withdrawn by their peers. Journal of Abnormal Psychology, 27, 115-123.Shamir-Essakow, G., Ungerer, J. A., \& Rapee, R. M. (2005). Attachment, behavioral inhibition, and anxiety in preschool children. Journal of Abnormal Child Psychology, 33, 131-143. 
Shanahan, L., McHale, S. M., Crouter, A. C., \& Osgood, D. W. (2008). Linkages between parents' differential treatment, youth depressive symptoms, and sibling relationships. Journal of Marriage and Family, 70(2), 480-494.

Shulman, S., Elicker, J., Sroufe, L. A. (1994). Stages of friendship growth in preadolescence as related to attachment history. Journal of Social and Personal Relationships, 11(3), 341-361.

Spangler G, Schieche M. 1998. Emotional and adrenocortical responses of infants to the Strange situation: The differential function of emotional expression. International Journal of Behavioral Development, 22: 681-706.

Sroufe, L. A., \& Fleeson, J. (1986). Attachment and the construction of relationships. In W. Hartup, \& Z. Rubin (Eds.), Relationships and Development. New York: Cambridge Univ. Press.

Stewart, R. B., \& Marvin, R. S. (1984). Sibling relations: The role of conceptual perspective-taking in the ontogeny of sibling caregiving. Child Development, 55(4), $1322-1332$.

Stewart, S. L, \& Rubin, K. H. (1995). The social problem solving skills of anxiouswithdrawn children. Development and Psychopathology. 7, 323-336.

Stocker, C. M. (1994). Children's perceptions of relationships with siblings, friends, and mothers: Compensatory processes and links with adjustment. Journal of Child Psychology and Psychiatry, 35(8), 1447-1459.

Stocker, C. M., Burwell, R. A., \& Briggs, M. L. (2002). Sibling conflict in middle childhood predicts children's adjustment in early adolescence. Journal of Family Psychology, 16(1), 50-57. 
Stocker, C., \& Dunn, J. (1990). Sibling relationships in childhood: Links with friendships and peer relationships. British Journal of Developmental Psychology, 8(3), 227-244.

Stocker, C., Dunn, J., \& Plomin, R. (1989). Sibling relationships: Links with child temperament, maternal behavior, and family structure. Child Development, 60(3), 715-727.

Stormshak, E. A., Bellanti, C. J., \& Bierman, K. L. (1996). The quality of sibling relationships and the development of social competence and behavioral control in aggressive children. Developmental Psychology, 32(1), 79-89.

Sullivan, H. S. (1953). The interpersonal theory of psychiatry. New York: Norton \& Co.

Sutton-Smith, B., \& Rosenberg, B. G. (1970). The sibling. Oxford, England: Holt, Rinehart, \& Winston.

Tabachnick, B. G., \& Fidell, L. S. (2007). Experimental design using ANOVA. USA: Thompson Brooks/Cole.

Teti, D. M., \& Ablard, K. E. (1989). Security of attachment and infant-sibling relationships: A laboratory study. Child Development, 60(6), 1519-1528.

Tucker, C. J., McHale, S. M., \& Crouter, A. C. (2008). Links between older and younger adolescent siblings' adjustment: The moderating role of shared activities. International Journal of Behavioral Development, 32(2), 152-160.

Tucker, C. J., Updegraff, K. A., McHale, S. M., \& Crouter, A. C. (1999). Older siblings as socializers of younger siblings' empathy. Journal of Early Adolescence. Special Issue: Prosocial and Moral Development in Early Adolescence, Part II, 19(2), 176198. 
Updegraff, K. A., McHale, S. M., \& Crouter, A. C. (2002). Adolescents' sibling relationship and friendship experiences: Developmental patterns and relationship linkages. Social Development, 11(2), 182-204.

van Brakel, A. M. L., Muris, P., Bögels, S. M., \& Thomassen, C. (2006). A multifactorial model for the etiology of anxiety in non-clinical adolescents: Main and interactive effects of behavioral inhibition, attachment and parental rearing. Journal of Child and Family Studies, 15(5), 569-579.

Vandell, D. L., Minnett, A. M., \& Santrock, J. W. (1987). Age differences in sibling relationships during middle childhood. Journal of Applied Developmental Psychology, 8(3), 247-257.

Vandell, D. L., \& Wilson, K. S. (1987). Infant's interactions with mother, sibling, and peer: Contrasts and relations between interaction systems. Child Development, 58(1), 176-186.

Volling, B. L., Youngblade, L. M., \& Belsky, J. (1997). Young children's social relationships with sibling and friends. American Journal of Orthopsychiatry, 67, 102111.

Vygotsky, L. S., Hanfmann, E., \& Vakar, G. (Eds). (1962). Thought and language. New York: M.I.T. Press and Wiley.

Welsh, M., Parke, R. D., Wideman, K., \& O’Neil, R. (2001). Linkages between children's social and academic competence: A longitudinal analysis. Journal of School Psychology, 39, 463-482.

Wichmann, C., Coplan, R. J., \& Daniels, T. (2004). The social cognitions of socially withdrawn children. Social Development, 13, 377-392. 
Winnicott, D. W. (1992). Through paediatrics to psycho-analysis: Collected papers. Philadelphia, PA, US: Brunner/Mazel.

Wojlawowicz, J. C., Burgess, K. B., Rubin, K. H., Rose-Krasnor, L., \& Booth, C. B. (2002). The stability and quality of shy/withdrawn and aggressive children's best friends. In K. Burgess \& F. Vitaro (co-chairs), The qualities and functions of friendship in the case of shyness/withdrawal and aggression. Symposium conducted at the $17^{\text {th }}$ Biennial Meeting of the International Society for the Study of Behavioral Development, Ottawa, Canada.

Youngblade, L. M., \& Dunn, J. (1995). Social pretend with mother and sibling: Individual differences and social understanding. In A. D. Pellegrini (Ed.), The future of play theory: A multidisciplinary inquiry into the contributions of Brian SuttonSmith. (pp. 221-239). Albany, NY, US: State University of New York Press.

Younger, A. J., \& Boyko, K. A. (1987). Aggression and withdrawal as social schemas underlying children's peer perceptions. Child Development, 58(4), 1094-1100.

Younger, A., Gentile, C., \& Burgess, K. (1993). Children's perceptions of social withdrawal: Changes across age. In K. H. Rubin, \& J. B. Asendorpf (Eds.), Social withdrawal, inhibition, and shyness in childhood (pp. 215-235). Hillsdale, NJ, England: Lawrence Erlbaum Associates, Inc.

Zahn-Waxler, C., Radke-Yarrow, M., \& Brady-Smith, J. (1977). Perspective-taking and prosocial behavior. Developmental Psychology, 13(1), 87-88.

Zimbardo, P. G. (1977). Shyness: What is it and what to do about it. Reading, MA: Addison-Wesley. 
Zuckerman, M. (1994). Impulsive unsocialized sensation seeking: The biological foundations of a basic dimension of personality. In J. E. Bates, \& T. D. Wachs (Eds.), Temperament: Individual differences at the interface of biology and behavior. (pp. 219-255). Washington, DC, US: American Psychological Association. 
Shyness and Sibling Relationships109

Appendix A: Information and Consent Form

\section{With a little help from my brother or sister: The Carleton Sibling Study \\ Carleton University, 2009}

\section{Dear Parent,}

I am writing to ask your permission to allow your child to participate in a study that is being conducted by researchers from Carleton University at your child's preschool/daycare. We are trying to learn more about how children's relationships with their brothers or sisters might be related to their social relationships with friends at preschool. Although we are particularly interested in sibling relationships, families with only one child will also be included in the study.

There is a long history of interest in the potential "differences" between only-children, first-born, and later-born children. Researchers have wondered about children's social experiences at home with (or without) siblings, and how this might be related to their social experiences outside of the home. In this study, we are particularly interested in the sibling relationships of shy and sociable children. Children who are shy are cautious in social situations, and often take time to "warm up" when meeting new people. Children who are more sociable feel very comfortable with others and often initiate social contacts. We hope that the results from this study will help us understand the unique links between shy and sociable children's relationships at home and their relationships at school. Here is a more detailed description of what this project will involve (if you choose to participate):

Parents: Parents are being asked to complete some short questionnaires. The first concerns background information that will be used only to characterize this sample. Parents will also be asked to fill out a questionnaire regarding your child's social behaviours. For parents with more than one child - you will also be asked to fill out another short questionnaire on your child's relationship with their sibling closest in age. These questionnaires are attached for your inspection. If you agree to participate in this study - please complete the attached questionnaires and return them to your child's teacher along with the signed consent form (sealed in the envelope provided). You are free to not answer any questions that you choose to omit.

Children: Children will be invited to participate in a short (10 minute) interview with a trained research assistant. Interviews will be conducted without the child being removed from the classroom, during a time period selected to minimize the disruption of your child's normal daily routine. The questions concern how your child feels about interacting with their friends at preschool, as well as how they get along with their sibling. Your child will be reminded that they do not have to answer any questions they don't want to, and of course, they are free to end the interview at any time. 
Teachers: Your child's teacher will also be asked to fill out some questionnaires concerning your child's behaviour at preschool. These questionnaires concern, for example, how your child plays in class, and how he/she interacts with other children.

The data collected in this study will be strictly confidential and will be made available only to researchers associated with this project. All questionnaires will be coded with numbers (to match parent and child data) and not participant names, meaning that the information you provide will be kept anonymous.

This study has been approved by the Carleton University Ethics Committee for Psychological Research. If you have any questions related to this study and/or concerns about your child as a result of participation in this study, please feel free to contact me directly at 520-2600, ext. 1979, (or via email at: agraham@connect.carleton.ca) or my supervisor, Dr. Robert Coplan at 520-2600, ext. 8691 (or via email at: robert_coplan@connect.carleton.ca). If your child is experiencing any social or emotional difficulties, here are some resources you might find helpful: www.helpforkids.com, http://kidshealth.org. Should you have any ethical concerns about this study, please contact Dr. A. Parush (Chair, Carleton University Ethics Committee for Psychological Research, 520-2600, ext. 6026) or Dr. J. Mantler (Chair, Dept. of Psychology, 520-2600, ext. 4173). If you would like to learn more about children's sibling relationships and social development, there are numerous websites on these topics (e.g., http://www.cfw.tufts.edu/, www.familytlc.net/sibling_preteen.html) as well and books for parents related to siblings (e.g., Sibling Without Rivalry: How To Help Your Children Live Together So You Can Live Too, by A \& Faber) and shyness (e.g., The Shy Child: Helping Children Triumph Over Shyness, by W. K. Swallow).

Sincerely,

\author{
Allison Graham \\ M.A. Candidate \\ Department of Psychology \\ Carleton University \\ Robert J. Coplan, Ph.D. \\ Professor, Department of Psychology \\ Carleton University
}


CONSENT FORM - Exploring the Effects of Sibling Relationships Study

The information collected for this project is confidential and protected under the Municipal Freedom of Information and Privacy Act, 1989.

Date:

(name of child - please print)

(name of parent or guardian - please print

Please check one:

I give my permission for my child and I to participate in the With a little help from my brother and sister: The Carleton Sibling Study.

I do not give my permission for my child and I to participate in the With a little help from my brother and sister: The Carleton Sibling Study.

(signature of parent or guardian)

Please return the signed consent form and questionnaires to your child's teacher (sealed in the enclosed envelope) as soon as possible even if you are not going to be participating in the study.

If you would like to receive a summary of the findings from this study please indicate an e-mail address or a mailing address in which we can send the results. Please note that only group results will be provided, and not individual feedback about particular children. 
Appendix B: Scripts for Recruitment and Child Individual Interviews

Recruitment Script - Preschool Directors and Teachers

Dear Preschool/Daycare Directors,

My name is Allison Graham; I am a student at Carleton University. I was wondering if your preschool/daycare would be interested in participating in a study I am conducting for my M.A. thesis which is under the supervision of Dr. Robert Coplan. This study has been approved by the Carleton University Ethics Committee for Psychological Research. I am interested in how children's sibling relationships might be related to their relationships with other children at preschool/daycare. We are particularly interested in the sibling relationships of shy children who may have trouble interacting with other children at preschool. However, only children and children of varying sociability will be included in the study. Children 4 and 5 years of age will be included in the study.

This study will involve parents, teachers and children, however every effort will be taken to minimize disruption of daily activities. Parents will be asked to fill out some short questionnaires related to background information, their child's social behaviours and their child's relationship with a sibling. Teachers will also be asked to complete a short questionnaire concerning children's behaviour at preschool (only for selected children who are participating in the study). Children, who have parental consent, will be invited to participate in a short (10 minute) individual interview with a trained researcher, preferably without leaving the classroom. The questions concern how children feel about interacting with their friends at school, as well as how they get along with their sibling. It is very important to note that kids will be aware that they do not have to answer any question that they don't want to and can end the interview at any time. All information will be kept confidential and anonymous. Would this project be something that your preschool/daycare might be interested in taking part in?

If you are interested in participating in this study please contact me through email or phone at Please also let me know how many children are in your 4 or 5 years old programs.

Sincerely,

Allison Graham

M.A. Candidate,

Department of Psychology

Carleton University

\section{Child Interview - Information Script}

$\mathrm{Hi}$, my name is Allison; I am a student at Carleton University. I am doing a project on children your age and how you get along with your sisters and brothers and will be asking 
you a few questions. You should know that this is not a test and there are no right or wrong answers. You don't have to answer any questions that you don't want to and can stop at any time. The answers you give will be kept completely private; no one will see them other than myself. That means that I will not share your answers with your parents, your teachers, your friends, or anyone else. If you're ready, let's get started.

\section{Child Interview - Debriefing Script}

Thank you for helping me with my project. I was interested in your relationships with your brothers and sisters and how that changes how you feel about yourself. If any of the questions made you feel uncomfortable, you can talk to me about it while I'm here today. If you or your parents want to talk to me after today, my number is in the package we sent home to your parents. Are there any questions? Thanks again for participating and have a great day. 
Appendix C: Demographic Information

BACKGROUND INFORMATION

Child Name

Child Birth Date month day year Child Age (in years)

Boy Girl

Preschool/Daycare Teacher

Most frequent form of child care over the last two years (check one that most applies): At home with parent Child Care Center Homecare (i.e. small group of children in another home) Other (Specify)

Parent or Guardian 1: Relationship to Child Age

Highest formal education completed (check one):

elementary school high school diploma (or equivalent) community college (or equivalent) university degree graduate school degree

Ethnic group: Caucasian Asian Black (optional) Hispanic Aboriginal Other

Parent or Guardian 2 (if applicable): Relationship to Child Age Highest formal education completed (check one): elementary school high school diploma (or equivalent) community college (or equivalent) university degree graduate school degree

Ethnic group: Caucasian Asian Black (optional) Hispanic Aboriginal Other

Current Marital Status: Married or Common Law single Separated or Divorced Other (specify)

Is English the first language spoken in your home? Yes No

Number of children in family If child has more than one sibling - please select sibling closest in age: Sibling's Birth Date Age (in years)

Boy _ Girl (if applicable) month day year 
Appendix D: Parent Rated Child Shyness Questionnaire

$\underline{\text { Social Preference Questionnaire }}$

Name of child:

Please answer the items on this page about the behaviour of your child by circling one of the numbers following each item. We know that no item will apply to the child in every situation, but try to consider his/her usual or general behaviour. Please answer all questions-- there are no right or wrong answers.

\begin{tabular}{|c|c|c|c|c|c|}
\hline \multirow[b]{3}{*}{ 1. My child often seems content to play alone. } & \multicolumn{5}{|c|}{ How much is your child like that? } \\
\hline & \multicolumn{2}{|c|}{ Not at All } & \multicolumn{2}{|c|}{$\leftarrow \rightarrow$} & \\
\hline & 1 & 2 & 3 & 4 & 5 \\
\hline $\begin{array}{l}\text { 2. My child seems to want to play with other children, but is } \\
\text { sometimes nervous to. }\end{array}$ & 1 & 2 & 3 & 4 & 5 \\
\hline $\begin{array}{l}\text { 3. My child is just as happy to play quietly by his/herself than to } \\
\text { play with a group of children. }\end{array}$ & 1 & 2 & 3 & 4 & 5 \\
\hline 4. My child is happiest when playing with other children. & 1 & 2 & 3 & 4 & 5 \\
\hline $\begin{array}{l}\text { 5. My child will turn down social initiations from other children } \\
\text { because he/she is 'shy'. }\end{array}$ & 1 & 2 & 3 & 4 & 5 \\
\hline 6. My child often approaches other children to initiate play. & 1 & 2 & 3 & 4 & 5 \\
\hline $\begin{array}{l}\text { 7. My child 'hovers' near where other children are playing, without } \\
\text { joining in. }\end{array}$ & 1 & 2 & 3 & 4 & 5 \\
\hline 8. My child rarely initiates play activities with other children. & 1 & 2 & 3 & 4 & 5 \\
\hline $\begin{array}{l}\text { 9. If given the choice, my child prefers to play with other children } \\
\text { rather than alone. }\end{array}$ & 1 & 2 & 3 & 4 & 5 \\
\hline $\begin{array}{l}\text { 10. My child often watches other children play without } \\
\text { approaching them. }\end{array}$ & 1 & 2 & 3 & 4 & 5 \\
\hline $\begin{array}{l}\text { 11. Although he/she appears to desire to play with others, my child } \\
\text { is sometimes anxious about interacting with other children. }\end{array}$ & 1 & 2 & 3 & 4 & 5 \\
\hline
\end{tabular}


Appendix E: Teacher Rated Socio-Emotional Functioning

\section{Child Behaviour Scale}

\section{NAME OF CHILD} NAME OF TEACHER

Please consider the descriptions contained in each of the following items below and rate the extent to which each of these descriptions applies to this child, particularly in the context of his/her behaviour with peers. For example, circle 3-"Certainly applies" if the child often displays the behaviour described in the statement, circle 2-"Applies sometimes" if the child occasionally displays the behaviour, and circle 1-"Doesn't apply" if the child seldom displays the behaviour.

\section{1=Doesn't apply 2=Applies sometimes $\quad 3=$ Certainly applies}

$\begin{array}{llll}1 & 2 & 3 & 1\end{array}$. Not much liked by children

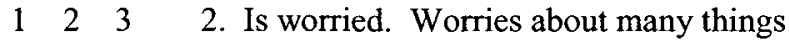

$\begin{array}{llll}1 & 2 & 3 & 3\end{array}$. Appears miserable, unhappy, tearful, or distressed

123 4. Tends to be fearful or afraid of new things or new situations

$\begin{array}{llll}1 & 2 & 3 & 5\end{array}$. Cries easily

1236 . Prefers to play alone

$\begin{array}{llll}1 & 2 & 3 & 7 \text { 7. Helps other children }\end{array}$

$\begin{array}{llll}1 & 2 & 3 & 8\end{array}$. Peers refuse to let this child play with them

$\begin{array}{llll}1 & 2 & 3 & 9\end{array}$. Shows a recognition of the feelings of others; is empathetic

$\begin{array}{llll}1 & 2 & 3 & 10 .\end{array}$. Not chosen as playmate by peers

123 11. Likes to be alone

$\begin{array}{llll}1 & 2 & 3 & 12 . \\ 12 & \text { Keeps peers at a distance }\end{array}$

$\begin{array}{llll}1 & 2 & 3 & 13 . \\ 13\end{array}$

$\begin{array}{llll}1 & 2 & 3 & 14\end{array}$. Seems concerned when other children are distressed

$\begin{array}{llll}1 & 2 & 3 & 15 \\ 15 & \text {. Kind toward peers }\end{array}$

$\begin{array}{llll}1 & 2 & 3 & 16 . \\ 16\end{array}$

$\begin{array}{llll}1 & 2 & 3 & 17\end{array}$. Is ignored by peers

$\begin{array}{llll}1 & 2 & 3 & 18 . \\ & \text { Cooperative with peers }\end{array}$

$\begin{array}{llll}1 & 2 & 3 & 19 .\end{array}$. Solitary child

1232 20. Shows concern for moral issues (e.g., fairness, welfare or others)

$\begin{array}{llll}1 & 2 & 3 & 21 .\end{array}$. Ridiculed by peers

$\begin{array}{llll}1 & 2 & 3 & 22 .\end{array}$. Avoids peers

123 23. Offers help or comfort when other children are upset

$\begin{array}{llll}1 & 2 & 3 & 24 \\ & \text {. Withdraws from peer activities }\end{array}$ 
Appendix F: Self-Perceptions of Social and Cognitive Competence

1a. This girl/boy is pretty good at puzzles.

b. This girl/boy isn't very good at puzzles.

2a. This girl/boy has lots of friends to play with.

b. This girl/boy doesn't have very many friends to play with.

3a. This girl/boy usually gets stars on her papers.

b. This girl/boy usually doesn't get stars on her papers.

4a. This girl/boy doesn't stay overnight at her friend's houses very often.

b. This girl/boy stays overnight at her friend's houses often.

5a. This girl/boy doesn't know the names of very many colours.

b. This girl/boy knows the names of many colours.

6a. This girl/boy has many friends to play games with.

b. This girl/boy doesn't have a lot of friends to play games with.

7a. This girl/boy isn't very good at counting.

b. This girl/boy is pretty good at counting.

8a. This girl/boy doesn't have very many friends to play with on the playground.

b. This girl/boy has lots of friends to play with on the playground.

9a. This girl/boy isn't very good at saying the alphabet.

b. This girl/boy is pretty good at saying the alphabet.

10a. This girl/boy usually gets asked to play with the other kids.

b. This girl/boy gets lonely sometimes because the other kids don't ask her to play.

11a. This girl/boy knows the first letter of her name.

b. This girl/boy has trouble remembering the first letter of her name.

12a. This girl usually doesn't get to eat dinner at friend's houses.

b. This girl usually gets to eat dinner at friend's houses. 
Appendix G: Child Loneliness Questionnaire

1. Is it easy for you to make new friends at preschool/daycare?

2. Do you like to hear stories?

3. Do you have other kids to talk to at preschool/daycare?

4. Are you good at working with other kids at preschool/daycare?

5. Do you watch T.V. a lot?

6. Is it hard for you to make friends at preschool/daycare?

7. Do you like preschool/daycare?

8. Do you have lots of friends at preschool/daycare?

9. Do you feel alone at preschool/daycare?

10. Can you find a friend when you need one?

11. Do you play outside a lot?

12. Is it hard to get kids in preschool/daycare to like you?

13. Do you like to learn about dinosaurs?

14. Do you have kids to play with at preschool/daycare?

15. Do you like singing songs?

16. Do you get along with other kids at preschool/daycare?

17. Do you feel left out of things at preschool/daycare?

18. Are there kids you can go to when you need help in preschool/daycare?

19. Do you like to paint and draw?

20. Is it hard for you to get along with the kids at preschool/daycare?

21. Are you lonely at preschool/daycare?

22. Do the kids at preschool/daycare like you?

23. Do you like playing games?

24. Do you have friends at preschool/daycare? 


\section{Appendix H: Child and Parent Sibling Appraisal Questionnaires}

\section{Child Sibling Appraisal Questionnaire}

I'm going to ask you some questions with these puppets. These 2 puppets we'll pretend are Erin, and these 2 puppets we'll pretend are you, but they're each a little different. I'm going to tell you something about each puppet and you tell me which puppet is like you or your sister/brother (i.e., Erin). Let's practice one: Erin likes dogs (hold up puppet). Erin doesn't like dogs (hold up other puppet). Which one is like Erin? Is that a lot like him/her or a little like him/her?

\begin{tabular}{|c|c|c|}
\hline $\begin{array}{l}\text { 1a. Erin is nice to me. } \\
\text { Erin is not nice to me. }\end{array}$ & A lot & A little \\
\hline $\begin{array}{l}\text { lb. I am mean to Erin. } \square \\
\text { I am not mean to Erin. }\end{array}$ & A lot & A little \\
\hline $\begin{array}{ll}\text { 2a. } & \text { I share with Erin. } \square \\
& \text { I do not share with Erin. }\end{array}$ & A lot & A little \\
\hline 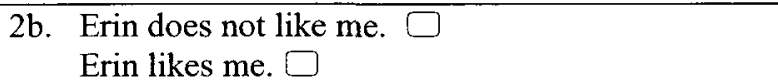 & A lot & A little \\
\hline $\begin{array}{l}\text { 3a. Erin does not like to do things with me. } \square \\
\text { Erin likes to do things with me. } \square\end{array}$ & A lot & A little \\
\hline $\begin{array}{l}\text { 3b. I do not try to hurt Erin. } \\
\text { I try to hurt Erin. } \square\end{array}$ & A lot & A little \\
\hline $\begin{array}{l}\text { 4a. I do not help Erin. } \square \\
\text { I help Erin. } \square\end{array}$ & A lot & A little \\
\hline $\begin{array}{l}\text { 4b. Erin does not fight with me. } \square \\
\text { Erin fights with me. } \square\end{array}$ & A lot & A little \\
\hline $\begin{array}{l}\text { 5a. Erin shares with me. } \square \\
\text { Erin does not share with me. } \square\end{array}$ & A lot & A little \\
\hline $\begin{array}{l}\text { 5b. I am nice to Erin. } \square \\
\text { I am not nice to Erin. } \square\end{array}$ & A lot & A little \\
\hline $\begin{array}{l}\text { 6a. I do not like to do things with Erin. } \square \\
\text { I like to do things with Erin. } \square\end{array}$ & A lot & A little \\
\hline $\begin{array}{l}\text { 6b. Erin does not help me. } \square \\
\text { Erin helps me. } \square\end{array}$ & A lot & A little \\
\hline $\begin{array}{l}\text { 7a. } \text { Erin is mean to me. } \square \\
\text { Erin is not mean to me. }\end{array}$ & A lot & A little \\
\hline $\begin{array}{l}\text { 7b. I am not a good a good brother/sister to Erin. } \\
\text { I am a good brother/sister to Erin. }\end{array}$ & A lot & A little \\
\hline $\begin{array}{l}\text { 8a. I get angry with Erin. } \square \\
\text { I do not get angry with Erin. } \square\end{array}$ & A lot & A little \\
\hline $\begin{array}{l}\text { 8b. } \text { Erin has good times with me. } \square \\
\text { Erin does not have good times with me. } \square\end{array}$ & A lot & A little \\
\hline $\begin{array}{ll}\text { 9a } & \text { Erin does not try to hurt me. } \square \\
& \text { Erin tries to hurt me. } \square\end{array}$ & A lot & A little \\
\hline $\begin{array}{l}\text { 9b. I have good times with Erin. } \square \\
\text { I do not have good times with Erin. }\end{array}$ & A lot & A little \\
\hline $\begin{array}{l}\text { 10a. I do not fight with Erin. } \\
\text { I fight with Erin. } \square\end{array}$ & A lot & A little \\
\hline $\begin{array}{l}\text { 10a. Erin is not a good brother/sister to me. } \\
\text { Erin is a good brother/sister to me. } \square\end{array}$ & A lot & A little \\
\hline $\begin{array}{l}\text { 11a. Erin gets angry with me } \square \\
\text { Erin doesn't get angry with me }\end{array}$ & A lot & A little \\
\hline $\begin{array}{l}\text { 11b. I do not like Erin. } \square \\
\text { I like Erin. } \square\end{array}$ & A lot & A little \\
\hline
\end{tabular}




\section{Parent Rated Sibling Appraisal Questionnaire}

Please indicate which statement is accurate regarding each of your children's behaviour to their sibling, and then indicate the degree to which the statement is like your child. Child $1=$ target child, Child 2 = sibling

Circle appropriate statement

Circle degree of likeness

\begin{tabular}{|c|c|c|}
\hline $\begin{array}{l}\text { 1a. Child } 1 \text { is nice to Child 2. } \square \\
\text { Child } 1 \text { is not nice to Child } 2 . \square\end{array}$ & A lot & A little \\
\hline $\begin{array}{l}\text { 1b. Child } 2 \text { is nice to Child } 1 . \square \\
\text { Child } 2 \text { is not nice to Child } 1 . \square\end{array}$ & A lot & A little \\
\hline $\begin{array}{l}\text { 2a. Child } 2 \text { does not like Child } 1 . \square \\
\text { Child } 2 \text { likes Child } 1 . \square\end{array}$ & A lot & A little \\
\hline $\begin{array}{l}\text { 2b. Child } 1 \text { does not like Child 2. } \square \\
\text { Child } 1 \text { likes Child 2. } \square\end{array}$ & A lot & A little \\
\hline $\begin{array}{l}\text { 3a. Child } 1 \text { does not like to do things with Child } 2 \square \\
\text { Child } 1 \text { likes to do things with Child } 2 \text {. } \square\end{array}$ & A lot & A little \\
\hline $\begin{array}{l}\text { 3b. Child } 2 \text { does not like to do things with Child } 1 . \square \\
\text { Child } 2 \text { likes to do things with Child } 1 \text {. } \square\end{array}$ & A lot & A little \\
\hline $\begin{array}{l}\text { 4a. Child } 2 \text { does not fight with Child } 1 . \square \\
\text { Child } 2 \text { fights with Child } 1 . \square\end{array}$ & A lot & A little \\
\hline $\begin{array}{l}\text { 4b. Child } 1 \text { does not fight with Child 2. } \\
\text { Child } 1 \text { fights with Child } 2 \text {. }\end{array}$ & A lot & A little \\
\hline $\begin{array}{l}\text { 5a. Child } 1 \text { shares with Child } 2 . \square \\
\text { Child } 1 \text { does not share with Child 2. }\end{array}$ & A lot & A little \\
\hline $\begin{array}{l}\text { 5b. Child } 2 \text { shares with Child } 1 . \square \\
\text { Child } 2 \text { does not share with Child } 1 . \square\end{array}$ & A lot & A little \\
\hline $\begin{array}{l}\text { 6a. Child } 2 \text { does not help Child 1. } \square \\
\text { Child } 2 \text { helps Child } 1 . \square\end{array}$ & A lot & A little \\
\hline $\begin{array}{l}\text { 6b. Child } 1 \text { does not help Child 2. } \\
\text { Child } 1 \text { helps Child } 2 . \square\end{array}$ & A lot & A little \\
\hline $\begin{array}{l}\text { 7a. Child } 1 \text { is mean to Child 2. } \\
\text { Child } 1 \text { is not mean to Child 2. }\end{array}$ & A lot & A little \\
\hline $\begin{array}{l}\text { 7b. Child } 2 \text { is mean to Child } 1 . \\
\text { Child } 2 \text { is not mean to Child } 1 .\end{array}$ & A lot & A little \\
\hline $\begin{array}{l}\text { 8a. Child } 2 \text { has good times with Child } 1 . \square \\
\text { Child } 2 \text { does not have good times with Child } 1 . \square\end{array}$ & A lot & A little \\
\hline $\begin{array}{l}\text { 8b. Child } 1 \text { has good times with Child } 2 . \square \\
\text { Child } 1 \text { does not have good times with Child 2. } \square\end{array}$ & A lot & A little \\
\hline $\begin{array}{l}\text { 9a. Child } 1 \text { does not try to hurt Child 2. } \\
\text { Child } 1 \text { tries to hurt Child } 2 .\end{array}$ & A lot & A little \\
\hline $\begin{array}{l}\text { 9b. Child } 2 \text { does not try to hurt Child } 1 . \square \\
\text { Child } 2 \text { tries to hurt Child } 1 \text {. }\end{array}$ & A lot & A little \\
\hline $\begin{array}{l}\text { 10a. Child } 2 \text { is not a good sibling to Child 1. } \\
\text { Child } 2 \text { is a good sibling to Child } 1 .\end{array}$ & A lot & A little \\
\hline $\begin{array}{l}\text { 10b. Child } 1 \text { is not a good sibling to Child } 2 . \square \\
\text { Child } 1 \text { is a good sibling to Child } 2 \text {. }\end{array}$ & A lot & A little \\
\hline $\begin{array}{l}\text { 11a. Child } 2 \text { gets angry with Child } 1 \square \\
\text { Child } 2 \text { doesn't get angry with Child } 1 \square\end{array}$ & A lot & A little \\
\hline $\begin{array}{l}\text { 11b. Child } 1 \text { gets angry with Child } 2 \square \\
\text { Child } 1 \text { doesn't get angry with Child } 2 \square\end{array}$ & A lot & A little \\
\hline
\end{tabular}

